
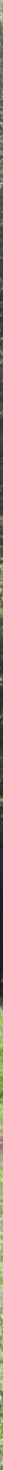

Vulnerability and adaptation strategies of dairy farming systems to extreme climate events in southwest Uganda

Results of CSA-PRA workshops 



\section{Vulnerability and adaptation strategies of dairy farming systems to extreme climate events in southwest Uganda}

Results of CSA-PRA workshops

Marion de Vries

This research was conducted by Wageningen Livestock Research as part of 'The Inclusive Dairy Enterprise' (TIDE) project. TIDE is commissioned and funded by the Embassy of the Kingdom of the Netherlands and implemented by SNV in Uganda.

Wageningen Livestock Research

Wageningen, January 2019

Report 1141 
De Vries, M., 2018. Vulnerability and adaptation strategies of dairy farming systems to extreme climate events in southwest Uganda. Results of CSA-PRA workshops. Wageningen Livestock Research, Wageningen, the Netherlands.

Prolonged droughts and excess rainfall are expected to increase in frequency and intensity in southwest Uganda as a result of climate change. The aim of this study was to identify vulnerability and adaptation strategies of dairy farming systems in southwest Uganda to extreme climate events. Results showed dairy farming systems have been affected by extreme weather mainly through reduced quantity and quality of feed and water resources, and increased disease incidence. This impacted production and reproductive performance of herds, and increased disease incidence and mortality. Adaptation strategies of farmers included management of feed and water resources, migration of cattle, and reduction of the herd size.

This report can be downloaded for free at https://doi.org/10.18174/468558 or at www.wur.nl/livestock-research (under Wageningen Livestock Research publications).

\section{(C) 2019 Wageningen Livestock Research}

P.O. Box 338, 6700 AH Wageningen, The Netherlands, T +31 (0)317 483953 ,

E info.livestockresearch@wur.nl, www.wur.nl/livestock-research. Wageningen Livestock Research is part of Wageningen University \& Research.

All rights reserved. No part of this publication may be reproduced and/or made public, whether by print, photocopy, microfilm or any other means, without the prior permission of the publisher or author.

Wageningen Livestock Research is NEN-EN-ISO 9001:2015 certified.

All our research commissions are in line with the Terms and Conditions of the Animal Sciences Group. These are filed with the District Court of Zwolle. 


\section{Table of contents}

$\begin{array}{ll}\text { Summary } & \mathbf{5}\end{array}$

$\begin{array}{lll}1 & \text { Introduction } & 7\end{array}$

$\begin{array}{llr}2 & \text { Methods } & 8\end{array}$

2.1 CSA-PRA tool $\quad 8$

2.2 Workshop locations $\quad 8$

2.3 Facilitators 9

2.4 Organization $\quad 10$

3

$\begin{array}{ll}\text { Results } & 11\end{array}$

$\begin{array}{lll}3.1 & \text { Characteristics of participating farms } & 11\end{array}$

3.2 Impacts of climate variability 13

3.2.1 'Normal year $\quad 13$

$\begin{array}{ll}3.2 .2 \text { Prolonged droughts } & 17\end{array}$

3.2.3 Excess rainfall 18

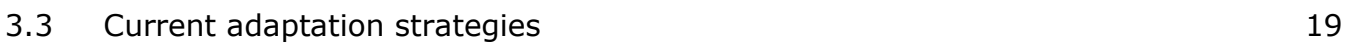

$\begin{array}{lll}3.4 & \text { Preferred adaptation options } & 20\end{array}$

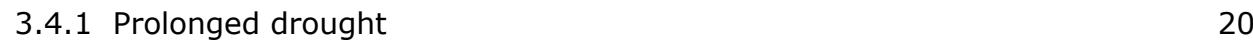

$\begin{array}{ll}3.4 .2 \text { Excess rainfall } & 21\end{array}$

3.5 Barriers and opportunities for adaptation $\quad 21$

4 Discussion \& conclusions $\quad 23$

$\begin{array}{ll}\text { Acknowledgements } & 26\end{array}$

$\begin{array}{ll}\text { References } & \mathbf{2 7}\end{array}$

Appendix 1 Preferred adaptation options during prolonged droughts 29

Appendix 2 Preferred adaptation options during excess rainfall 31 


\section{Summary}

Extreme climate events such as prolonged droughts and excess rainfall are expected to increase in frequency and intensity in southwest Uganda as a result of climate change. These changes can adversely affect dairy farming in Uganda through reduced water and feed availability and quality, and increased risks of animal diseases. A first step towards improving climate resilience of dairy farms is to understand how climate variability affects dairy farming systems and communities, and how farmers are currently coping with climate variability, especially in extremely dry or extremely wet years. The aim of this study was to identify current vulnerability and adaptation strategies of dairy farms in southwest Uganda to climate variability and extreme climate events.

\section{Methods}

A Climate Smart Agriculture Participatory Rural Appraisal (CSA-PRA) tool was developed for identification of characteristics, vulnerability and adaptation strategies of dairy farms to seasonal weather variation and extreme climate events. Six workshops were conducted with in total 103 dairy farmers in the districts Mbarara, Sheema, Isingiro and Kiruhura in southwest Uganda between May and June 2017. Results shown in this study represent perceptions of farmers participating in these workshops, and not author views.

\section{Characteristics of participating farms}

Most of the participating farmers had fenced perimeter and fenced paddocked grazing systems with Holstein-Friesian or Ankole Longhorn cattle breeds, or crosses. Cattle were fed mainly on natural pastures during rainy seasons, and supplemented with grown fodder, crop residues, and industrial byproducts in dry seasons. Most important water sources were shallow wells and water dams in the rainy season, whereas more water sources were used in the dry season (e.g. rivers and streams, ferried water).

\section{Effects of seasonal variability in a 'normal' year}

Southwest Uganda has a tropical climate with two dry seasons and two rainy seasons. Farmers indicated that in a 'normal' year the 1st dry season lasts from January to February or March; the 1st rainy season from March or April to May or June; the 2nd dry season from June or July to August or September; and the 2nd rainy season from September or October to December. Farmers indicated natural pastures and drinking water are insufficient in the 2nd dry season of a normal year in all districts, often lasting 3-4 months. In most farms the lack of natural pasture is compensated by crop residues (often from banana), but farmers indicated crop residues also become insufficient during the 2nd dry season. In Kiruhura district farmers did not feed alternative feeds to cope with reduced pasture in the dry seasons.

\section{Effects of prolonged drought}

In extremely dry years (e.g. 1999, 2016), prolonged drought led to increased mortality of calves and cows, increase in diseases (e.g. Anaplasmosis, Food and Mouth Disease), decrease in milk production levels, poor reproduction and abortion, and low market prices of animals because of poor body condition. Because pastures dried up this gave room to growth of less nutritious grasses. At the community level prolonged drought led to famines, poverty, outbreaks of human diseases, lack of (clean) water, people migrating to other areas, school dropout, conflicts and reduced markets for cattle products. Farmers in Sheema district indicated they are not much affected by extreme drought or excess rainfall because of relatively stable weather and their area being well adapted to extreme weather conditions due to the presence of wetlands and trees.

\section{Effects of excess rainfall}

In extremely wet years (e.g. 2012), excess rainfall caused increased outbreaks of cattle diseases (especially tick borne diseases like East Coast Fever, but also foot rot, Trypanosomiasis, pneumonia), and lower milk yields because cattle were affected by diseases, insufficient feeding time, and rotting of 
pastures due to floods. Some farmers indicated increased milk production levels of cows that were not affected by diseases. At the community level excess rainfall caused food shortages due to crop failure, outbreaks of human diseases, infrastructure and houses being destroyed (with higher transport costs), and land conflicts.

Adaptation strategies to extreme weather

Adaptation strategies of farmers to prolonged drought and excess rainfall included measures to increase availability of feed and water resources (alternative feeds, rotational grazing, weeding, feeding at night, renting land), reduction of the herd size, and migration of cattle. In open grazing systems in Rwempogo in Kiruhura district, reduction of the herd size and migration of cattle were the only coping strategies.

Most preferred short-term adaptation options for periods of prolonged drought included selling off cattle, migrating cattle, alternative feeds, and ferrying water. Preferences differed slightly among districts. In all districts farmers indicated construction of bigger dams was preferred as a long-term adaptation option, besides clearing farm fields and fencing. Most preferred adaptation options for excess rainfall were deworming and vaccination, migration of cattle, construction of trenches to direct water flows, and fencing farms.

\section{Conclusions and recommendations}

It was concluded dairy farming systems in southwest Uganda are affected by climate variability mainly through the reduced quantity and quality of feed and water resources, and changes in disease incidence. This affects production and reproductive performance of herds, morbidity and mortality. Farmers currently use various strategies to cope with these challenges, including management of feed and water resources, migration of cattle, and reduction of the herd size. As current adaptation strategies seemed to be focused mostly on coping with effects of extreme climate events, other adaptation strategies for prevention and mitigation of climate risks need to be explored. Measures should be tailored to the local geographical and socio-economic context of farms and the specific type of farming system (e.g. open vs. fenced grazing system). Promising adaptation options should be identified and tested locally with farmers in different locations. 


\section{Introduction}

Dairy farmers in southwest Uganda have always adapted to climate variability, being exposed to seasonal weather variations and extreme climate events. Due to climate change, however, the mean annual temperature and number of hot days are expected to increase, as well as the frequency and intensity of extreme climate events (particularly droughts and floods; UNDP, 2012; MAAIF and MWE, 2016; IPCC, 2013). This may affect dairy farming systems through (i) changes in the quality and quantity of water and feed, (ii) increased animal heat stress, and (iii) increased risks of cattle diseases (Thornton et al., 2009). Dairy farmers in the Ugandan cattle corridor have indicated that they are already experiencing changes in climate (e.g. Nimusiima et al., 2013; MWE, 2015a; Kirui et al., 2015). Potential impacts of changes in climate and climate variability are not that well understood, however, particularly as regards how the food security of vulnerable households may be affected (Thornton and Herrero, 2014).

Around $73 \%$ of the Ugandan population is employed in agriculture, with most people depending on subsistence farming (MAAIF, 2010). Livestock contributes about $17 \%$ to agricultural GDP, and dairy farming contributes about 40-50\% to livestock-related GDP (Balikowa, 2011; UNDP, 2017). The Ugandan dairy sector is growing at a rate of $8-10 \%$ per year, and milk has been identified as one of the 10 commodities of focus for accelerating growth of the agricultural sector (Agriterra, 2012). Adverse effects of climate change may undermine sector growth (MWE, 2015b). Dairy farms in Uganda are vulnerable to the consequences of climate change because of extensive reliance on rainfed forages, and persistent poverty limiting the capacity to adapt (Boko et al., 2007; Kirui et al., 2015). Climate change may amplify the climate-related challenges the dairy sector is currently dealing with, such as the decline in the quantity and quality of pastures during the dry season, invasion of unpalatable low quality grasses and bush encroachment due to overgrazing, and progressive shrinking of grazing land (NAMA Uganda; IPCC, 2014).

Climate-Smart Agriculture (CSA) is set as a key priority by the Government of Uganda (MAAIF and MWE, 2016; MWE 2015a). CSA is an integrative approach that strengthens food security, climate adaptation and climate mitigation. In the Climate-Smart Agriculture Program (2015-2025; MAAIF and MWE, 2016), Uganda's agricultural sector works towards reducing vulnerability to climate change risks. The sector aims to realize this by investing in measures that increase productivity and efficiency of agricultural systems, and that enhance adaptation and resilience of farming systems while contributing to reducing emissions intensity from the sector (MAAIF and MWE, 2016).

So far little research has been published on the potential effects of climate change on livestock in general (Thornton et al., 2015), and Ugandan dairy farming systems in specific. Changes in overall annual rainfall and temperature are expected to have little direct impact on dairy production (MAAIF, 2015), but it has been suggested that increases in droughts, floods, and animal diseases may have larger impacts. Kirui et al. (2015) found a relation between historic climate patterns, particularly the increasing dry spell, and increased livestock disease incidences, shortage of feed resources, and reduced milk production levels in Wakiso District in Uganda. Estimating impacts from future extreme weather events is complicated, however, because prediction of these events comes with large uncertainties.

A first step towards improving the climate resilience of dairy farms in southwest Uganda is to improve understanding of the nature and potential impacts of extreme climate events on dairy farming systems and their communities, and to know current coping strategies of farmers. The aim of this study, therefore, was to identify vulnerability and current adaptation strategies of dairy farming systems in southwest Uganda to climate variability ${ }^{1}$ and to extreme climate events ${ }^{2}$. The study focused on four districts in the southwestern milk-shed of Uganda: Mbarara, Sheema, Isingiro and Kiruhura.

\footnotetext{
${ }^{1}$ Climate variability refers to variations in the mean state and other statistics (such as standard deviations) of the climate on all spatial and temporal scales beyond that of individual weather events (IPCC, 2013).

${ }^{2}$ An extreme weather event is an event that is rare at a particular place and time of year. When a pattern of extreme weather persists for some time, such as a season, it may be classed as an extreme climate event, especially if it yields an average or total that is itself extreme (e.g. drought or heavy rainfall over a season; IPCC, 2013).
} 


\section{Methods}

\section{$2.1 \quad$ CSA-PRA tool}

The Climate Smart Agriculture Participatory Rural Appraisal (CSA-PRA) is a tool for assessing characteristics of local dairy farming systems and identifying current vulnerability and adaptation strategies of farmers to climate variability and extreme climate events. It is a mixed method approach that draws on participatory bottom-up, qualitative, and quantitative tools to assess the heterogeneity of local contexts, and prioritize context-specific adaptation options. The CSA-PRA tool for dairy farming systems in SW Uganda developed in this study was adapted from the CSA-PRA tool for crop production systems developed by Mwongera et al. (2015).

\subsection{Workshop locations}

Six workshop sessions ${ }^{3}$ were conducted with a total of 103 dairy farmers in southwest Uganda between May and June 2017. The 6 workshops were conducted in 4 administrative districts of SW Uganda:

- Mbarara district: Karama Parish, Nyakaijo Division; Kashaka Parish, Bubaare subcounty.

- Sheema District: Karera parish, Bugongi County.

- Isingiro District: Bukanga Parish, Endiizi Town Council.

- Kiruhura district: Kyampangara village, Ibaare II Parish, Kazo Subcounty; Rwempogo village, Nyakahita sub county.

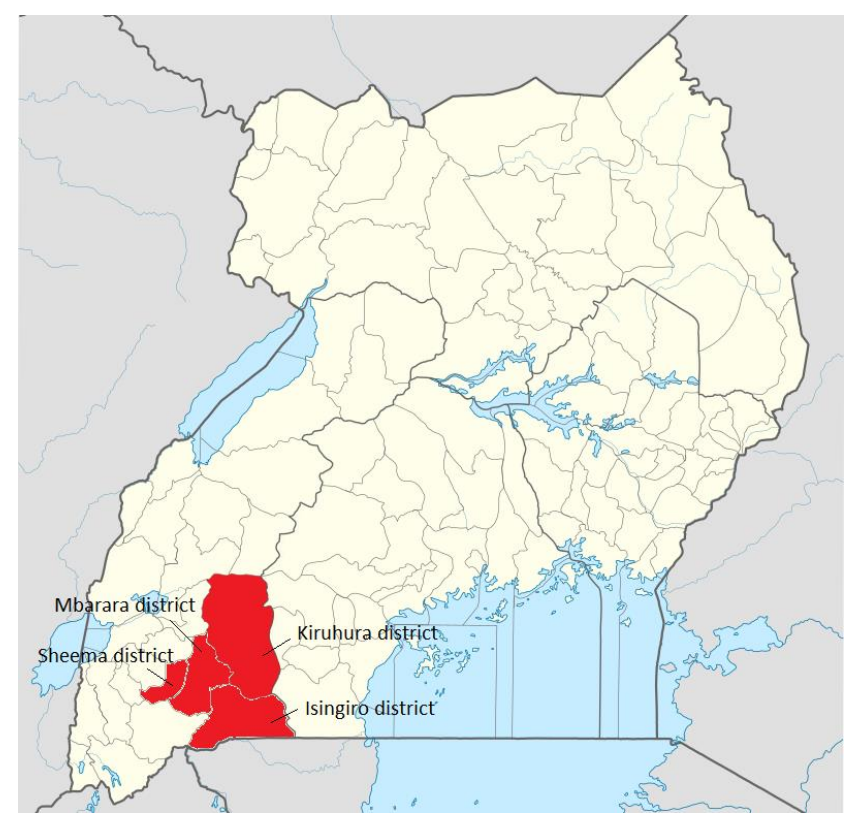

Figure 1 Map of Uganda.

These districts were chosen because they belonged to the 6 districts in the SNV TIDE project ${ }^{4}$, were generally known to have a higher probability of experiencing climate variability, and covered the two agro-ecological zones in the SNV TIDE operational area. Sheema district belongs to the South Western Farmlands Agro-Ecological Zone (AEZ) defined by MAAIF (2010), Kiruhura districts and Isingiro district belong to the Pastoral Rangelands AEZ, and Mbarara district is located in both AEZs. Southwestern Uganda has a tropical climate with a bimodal rainfall pattern and moderate temperatures (Figure 2). Mean elevation ranges from about $1200-1500 \mathrm{~m}$ in the 4 districts.

\footnotetext{
${ }^{3}$ A minimum of 3 workshop sessions is recommended across the study site to limit bias (Mwongera et al., 2015).

${ }^{4}$ 'The Inclusive Dairy Enterprise' (TIDE) project (http://www.snv.org/project/inclusive-dairy-enterprise-tide).
} 

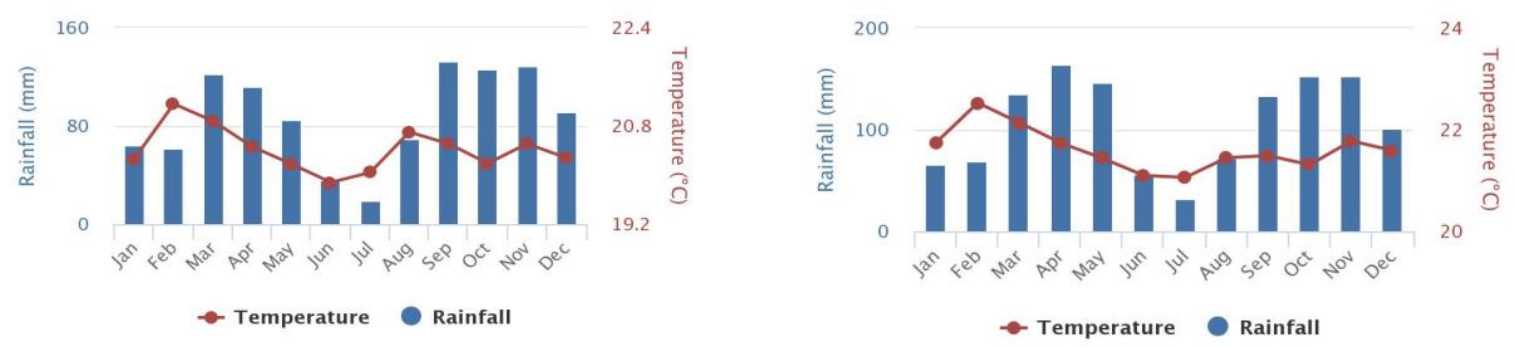

Figure 2 Average monthly rainfall and temperature between 1991 and 2015 in Mbarara (left figure; UGA location: -0.61, 30.61; elevation $1420 \mathrm{~m}$ ) and Nyakahita sub county in Kiruhura district (right figure; UGA location: -0.41, 31.07; elevation $1267 \mathrm{~m}$ ). Source: World Bank Climate Change Knowledge Portal (http://sdwebx.worldbank.org/climateportal, accessed December 2018).

Dairy production systems in the four districts can be described as follows:

- Mbarara district: Main sources of livelihoods are dairy, matooke (variety of banana), coffee and beef (cattle, goats, and sheep). Maize planting for human and fodder production is gaining prominence. Land holding are smaller than those of Kiruhura but larger than those of Sheema. Land is flat with few raised areas.

- Sheema district: Mixed farming systems are common with commercial purpose (tea, apiary, coffee, dairy, tree production) or subsistence (food crops, matooke, maize, millet, beans). Farms are on small land holdings ( $<5 \mathrm{ha}$ ), with growing land pressure. Dairy production systems are mainly zero grazing and fenced paddock/perimeter grazing systems. Land is hilly with many small valleys and wet lands.

- Isingiro district: Main sources of livelihood are dairy, beef and matooke. The grazing system is mainly open grazing and fenced perimeter. Zero grazing has been introduced in the hilly areas. Land holdings are big for the commercial farmers but small for the subsistence farmers. Some areas are flat while others are hilly. The districts is a neighbor to both Tanzania and Rwanda, with River Kagera passing near the district. This district is prone to drought conditions.

- $\quad$ Kiruhura district: Main source of livelihood is livestock (dairy, beef, goats) though crop farming (matooke, maize, beans) are gaining prominence, besides maize for fodder production. The area is a savannah kind of vegetation with few trees. Land is flat with few hilly places. Land holdings are quite large > 50 acres per house hold. The district neighbors to one of the biggest game reserves in the region.

\subsection{Selection of farmers}

The workshops were introduced at the local dairy cooperatives as meetings for cooperatives' members to share their understanding of climate change issues in their locality. The invitation was not an open call, rather, the cooperatives were asked to select farmers to attend the meetings voluntarily. The cooperatives were asked to select dairy farmers representative of the local population (i.e. with respect to gender, age, income, farming system, ethnic groups and agro-ecological zones). The participants didn't receive any incentives to attend. Only lunch was provided at nearby restaurants after the meetings. 


\section{$2.4 \quad$ Facilitators}

The CSA-PRA team consisted of 4 facilitators: 1 person facilitating the overall workshop, and 3 facilitating smaller focus groups. Facilitators were selected based on their experience with holding workshops, background in dairy production, and fluency in English and the local language. Facilitators received a 3 -day training, including practicing of workshop activities in a farmer community.

\subsection{Organization}

Workshops were held at a centrally located place and time at which both men and women could feel comfortable attending. In the workshop, smaller focus groups of 8 to 10 participants were formed based on grazing system (open/fenced perimeter/fenced paddocked/zero-grazing).

The workshop was organized in two blocks:

- $\quad$ The first block was aimed at understanding the local situation, by characterizing dairy farms of participating farmers, feed and water resources, cattle breeds, and major challenges to dairy farming. Activities in the first block included a plenary and group discussion, and making a feed calendar per focus group. Results of the first block were mainly important for proper interpretation of results of the second block.

- The aim of the second block was to understand vulnerability to extreme climate events and preferred adaptation options. Vulnerability was assessed by creating a climate calendar in which perceived impacts of an extremely dry or wet year were identified. Preferred adaptation options were identified through pairwise ranking of climate adaption measures used by farmers.

All exercises were based on open questions (vs. closed). In other words, impacts and adaptation options were not pre-defined. After each workshop, facilitators prepared one report per focus group, including results of a pre-discussion with the cooperative's group leader, and results of the plenary and group discussions with farmers. In addition, the registration form, feed calendar, climate calendar, and pairwise ranking matrices were delivered. 


\section{Results}

\subsection{Characteristics of participating farms}

\section{Participants}

In total 103 dairy farmers participated in the 6 workshops, varying from 14 to 20 participants per workshop (Table 1). In most workshops both female and male farmers attended, except for the workshop in Kashaka in which only men attended. Of all participating farmers, $26 \%$ was female. Age of participants ranged from 19 to 84, with average age being similar across all workshops.

In all workshops farmers indicated they kept dairy cattle because it was a source of income and food. In addition, farmers mentioned cattle are a form of savings and provide manure for their crops. Heritage, prestige, dowry, and cattle being a source of employment were less often mentioned as reasons for keeping dairy cattle.

\section{Dairy herds}

Herd size varied substantially, from 1 to 100 cows per farm. Herd sizes were smallest in Mbarara and Sheema, and largest in Isingiro and Kiruhura. In Sheema, participating farmers kept less than 10 cows per farm. The fenced perimeter grazing system was dominant among farmers in Isingiro and Kiruhura, whereas the share of participating farmers with fenced perimeter and fenced paddocks was similar in Mbarara and Sheema. Only 3 participants had an open grazing system (in Rwempogo).

Hardly any of the participating farms were located in the valley, except for Kashaka, where $71 \%$ of the farms were in the valley. In the workshops in Bukanga, Karama and Kyampangara most participating farms were located on the mountain slope, in Karera most farms were on the plateau, and Rwempogo had a similar share of farms on the slope and the plateau.

Table 1 Characteristics of farmers participating in CSA-PRA workshops.

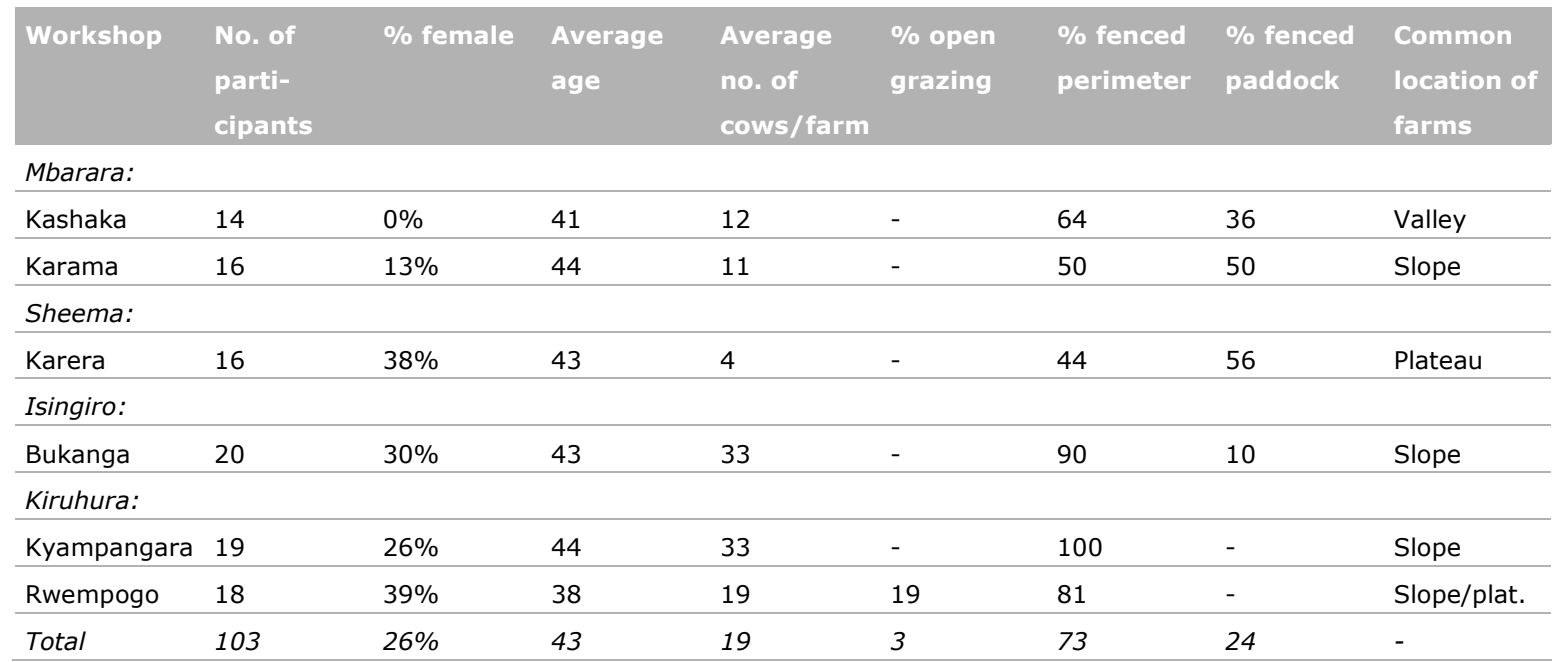

\section{Feed rations}

In all focus groups farmers indicated their cows were fed mainly on natural pastures and mineral salt during the rainy seasons, whereas cows were supplemented with crop residues and by-products in the dry seasons (Table 2). Maize bran was fed in both seasons in Mbarara and Isingiro, and as dry season feed in Sheema. Crop residues (mainly from banana) were the most common dry season feed in all districts, and were not fed in the rainy season. Other dry season feedstuffs were Napier grass, brewers mash, and Lablab in Mbarara; Napier grass in Sheema; and silage and molasses in Isingiro. Only in Rwempogo, cows were fed on natural pastures and mineral salt only throughout the year. 
Silage and hay were fed by fifteen farmers in Bukanga and Kyampangara (nearly all with a fenced perimeter system). For other farmers, reasons for not feeding conserved feed were: lack of knowledge and skills, it requires too much labour, high costs in combination with limited financial resources, or considered not important since they have natural pastures or local breeds "with a high feed conversion ratio".

In most focus groups natural pasture was the preferred feed source, because it is "cheap and readily available". Main grass species of natural pastures mentioned by farmers were Brachiaria ruziziensis (Congo grass), Themeda triandra (locally known as emburara), Sporobolus pyramidalis (locally known as egashi), Cynodon dactylon (star grass), and Panicum maximum (Guinea grass).

Table 2 Feed ration compositions in the rainy season and dry season (in parentheses) of farms participating in CSA-PRA workshops.

\begin{tabular}{|c|c|c|c|c|c|c|c|c|c|}
\hline Workshop & 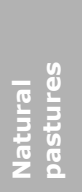 & $\frac{\frac{ \pm}{8}}{\frac{\pi}{50}}$ & $\frac{\sqrt{2}}{\frac{1}{2}}$ & $\frac{y}{3} \frac{y}{2}$ & $\begin{array}{l}\frac{8}{2} \\
\frac{10}{5} \\
\frac{5}{6} \\
\frac{2}{2} \\
\frac{2}{20}\end{array}$ & 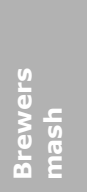 & $\frac{\frac{2}{10}}{\frac{2}{10}}$ & $\frac{0}{\frac{0}{\pi}}$ & $\begin{array}{l}y \\
0 \\
y \\
\frac{10}{0} \\
\frac{10}{2}\end{array}$ \\
\hline \multicolumn{10}{|l|}{ Mbarara: } \\
\hline Karama & $X(X)$ & $X(X)$ & $X(X)$ & $(X)$ & $(X)$ & $x$ & $(X)$ & & \\
\hline \multicolumn{10}{|l|}{ Sheema: } \\
\hline Karera & $X(X)$ & $X(X)$ & $(X)$ & $(X)$ & $X(X)$ & & & & \\
\hline \multicolumn{10}{|l|}{ Isingiro: } \\
\hline Rwempogo & $X(X)$ & $X(X)$ & & & & & & & \\
\hline
\end{tabular}

\section{Water sources}

Most important water sources during the rainy seasons were individual/valley/government water dams and shallow wells. During the dry season, more types of water sources are used than in rainy seasons, including water from rivers and streams, purchased water, and water from neighbours.

Breeds

Main cattle breeds used were Holstein-Friesian (HF) and Ankole Longhorn, or their crosses. In a few focus groups, Jersey, Guernsey and Ayrshire were used. In nearly all focus groups HF was the preferred breed, mainly because of high milk production. Only 3 out of the 103 farmers used artificial insemination (AI). Farmers indicated they did not want to use AI, mainly because AI is expensive, it causes reproduction problems (e.g. heat detection, number of repeats, reproductive disorders), AI services are inadequate or not available, and a lack of information/sensitization. In addition, in some focus groups farmers mentioned it is hard to maintain the breeds, and calves produced out of AI are easily affected by the dry season and more vulnerable to diseases and climate change. Farmers in Rwempogo with an open grazing system preferred the Ankole breed because they are hardy hence can walk very long distances in search of water and pasture, can withstand strong heat, and are more tolerant to ticks and diseases. They also stated Ankole cattle give better quality milk and ghee compared to exotic breeds.

\section{Animal and plant diseases}

Most important cattle diseases mentioned by farmers were East Coast Fever (ECF), anaplasmosis, mastitis, Foot and Mouth Disease, and lumpy skin disease, amongst other diseases. With regard to pests, weeds and diseases affecting fodder production, farmers indicated maize is affected by caterpillars, wildlife (birds and monkeys) and stalk borers, natural pastures are affected by termites, and Napier grass is affected by white sealers and Aphids. 


\section{Major challenges to dairy farming}

The challenges to dairy farming most often mentioned by farmers were: cattle diseases, poor quality drugs, low investment possibilities due to poverty, poor quality of pastures, climate change, low or instable milk prices, and shortage of land leading to overgrazing.

With regard to the role of weather patterns in these challenges, farmers argued that tick borne diseases (such as ECF) especially occur during the wet season, because abundant fodder harbours and favours tick multiplication. Farmers indicated most acaricides tend to be ineffective in the wet season as it is easily washed away from animals when it rains after spraying. Also, in the wet season, prices of milk are low due to availability of plenty of milk that surpasses the market demand. In the dry season, the lack of drinking water and natural pastures cause low milk production, and cattle become weak and die, or contract diseases. Cattle often have to walk long distances in search of water, with a deteriorating effect on health and milk production.

\subsection{Impacts of climate variability}

\subsection{1 'Normal year'}

Workshop participants showed how cattle drinking water and feed rations are impacted by seasonal variation in a 'normal' year by means of a 'feed calendar'. Lengths of the 4 seasons in a 'normal' year were perceived as follows by farmers:

- $\quad 1^{\text {st }}$ dry season: from January to February/March

- $\quad 1^{\text {st }}$ rainy season: from March/April to May/June

- $\quad 2^{\text {nd }}$ dry season: from June/July to August/September

- $\quad 2^{\text {nd }}$ rainy season: from September/October to December

\section{Sufficiency of feedstuffs and drinking water}

Farmer perceptions of the sufficiency of feedstuffs and drinking water in a normal year are shown in Figures 3a-d, with each figure representing results of one farmer focus group. Lines in these figures show which feedstuffs are fed, and when they are considered sufficient or insufficient in a normal year. For example, Figure 3a shows that farmers with a fenced perimeter grazing system in Karama parish indicated cattle were fed on natural pastures, rock salt and drinking water during the whole year, and cattle were fed on banana peelings and brewers mash in January and February, and from June to August. It also shows that natural pastures, banana peelings, brewers mash, and cattle drinking water were considered sufficient from November to June, and insufficient from July to October. Rock salt was considered sufficient throughout the year. Note that farmers only indicated whether feedstuffs and drinking were 'sufficient' or 'insufficient', but did not quantify sufficiency within these categories. In other words, the height (on the Y-axis) of the lines in Figures 3a-d does not indicate a higher or lower sufficiency.

Overall, Figures 3a-d show that, in a normal year:

- Natural pastures and drinking water are insufficiently available in the $2^{\text {nd }}$ dry season in all focus groups, often lasting 3-4 months (shown as a 'dip' in the trendline in Figure 2).

- In Kiruhura district, feed from natural pastures and drinking water are insufficient during 1-2 months the $1^{\text {st }}$ dry season as well. Also in some other focus groups feed from natural pastures are insufficient in the $1^{\text {st }}$ dry season (Bukanga group $A$; Karama fenced paddocked; Karera fenced paddocked).

- Sufficiency feed from natural pastures did not differ between fenced perimeter- and fenced paddocked grazing systems.

In most focus groups, the lack of natural pasture in the 2nd dry season is compensated by crop residues (often from banana) and maize bran. In most farms in Kiruhura, however, no alternative feeds are fed, causing that other strategies are needed to cope with insufficient feed availability. 
- Mineral salt was considered sufficient throughout the year in most focus groups.

- Maize bran was fed throughout the year in some focus groups, while in other groups it was fed in the dry season only. Most groups indicated that sufficient maize bran is available in the $2^{\text {nd }}$ dry season.

- Crop residues are most often fed in the dry season only, except for farmers in two focus groups in Mbarara who feed banana crop residues throughout the year. Crop residues are considered to be sufficiently available in the $1^{\text {st }}$ dry season but insufficient in the $2^{\text {nd }} d r y$ season.

- Napier grass was fed by farmers in only 3 focus groups. It was considered insufficiently available in the $2^{\text {nd }}$ dry season, but sufficient throughout the rest of the year.

- Farmers in focus groups with a perimeter system in Bukanga indicated hay and silage were used as alternative feeds when banana peelings become scarce during the second dry season (this was not indicated in the feed calendar, but at a different moment during the workshop).

Farmers explained that cattle drinking water is not only insufficient in dry seasons, but also that water was of poor quality because dams become muddy and wild animals cause reduced water quality. Also at the beginning of the rainy seasons, water is of poor quality.

In the discussions in Karera parish (Sheema district) farmers indicated that they have relatively stable weather and are not much affected by extreme drought or extreme wet seasons. However, this was not reflected in their 'feed calendar' (Figure 3b), in which they showed natural pastures and cattle drinking water are insufficiently available in the second dry season of a 'normal' year, nor in the 'climate calendar' in which they showed extremely dry or wet years had several types of impacts (Table $3 \& 4$ ). Average monthly rainfall in Karera parish in the past decennia does not differ much from amounts of rainfall in other workshop locations (World Bank Climate Change Knowledge Portal). 
Kashaka (perimeter)

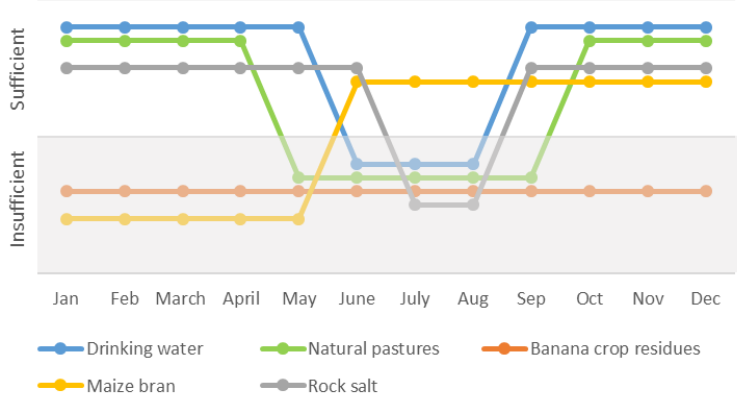

Karama (perimeter)

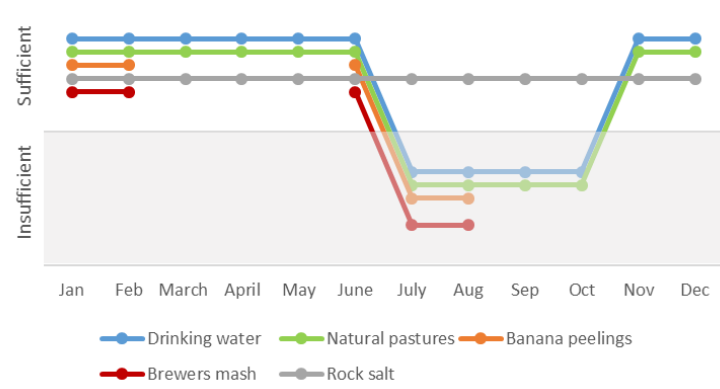

Kashaka (paddock)

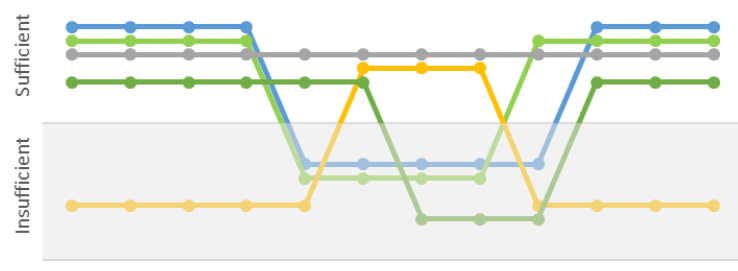

Jan Feb March April May June July Aug Sep Oct Nov Dec

$\multimap$ Drinking water $\longrightarrow$ Natural pastures $\multimap \longrightarrow$ Maize bran

$\multimap$ Napier grass $\rightarrow$ Rock salt

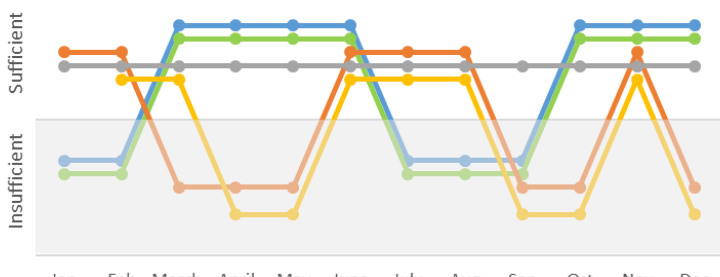

Jan Feb March April May June July Aug Sep Oct Nov Dec

$\multimap$ Drinking water $\multimap$ Natural pastures $\multimap$ Banana peelings

$\because$ Maize bran $\quad$ Rock salt

Figure 3a $\quad$ Perceived sufficiency of feedstuffs and cattle drinking water in a normal year, as perceived by farmers with fenced perimeter and fenced paddocked grazing systems in the workshops in Kashaka parish and Karama parish in Mbarara district.

Karera (perimeter)

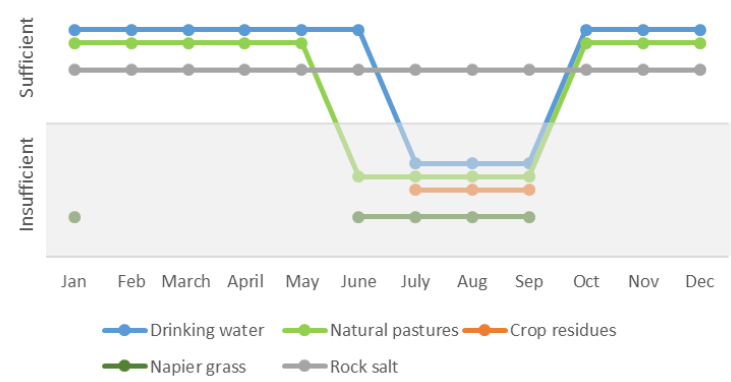

Karera (paddock)

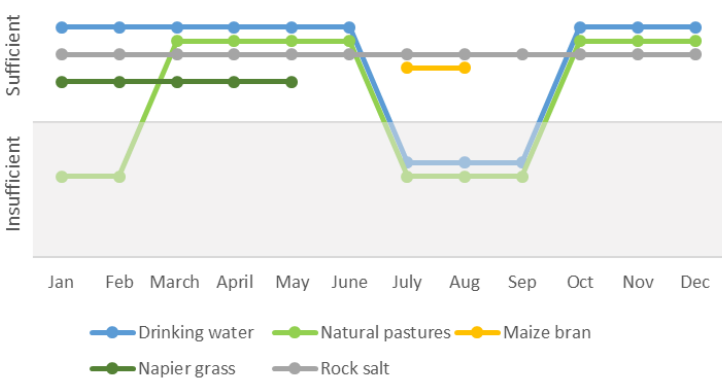

Figure $3 \boldsymbol{b} \quad$ Perceived sufficiency of feedstuffs and cattle drinking water in a normal year, as perceived by farmers with fenced perimeter and fenced paddocked grazing systems in the workshop in Karera parish in Sheema district. 

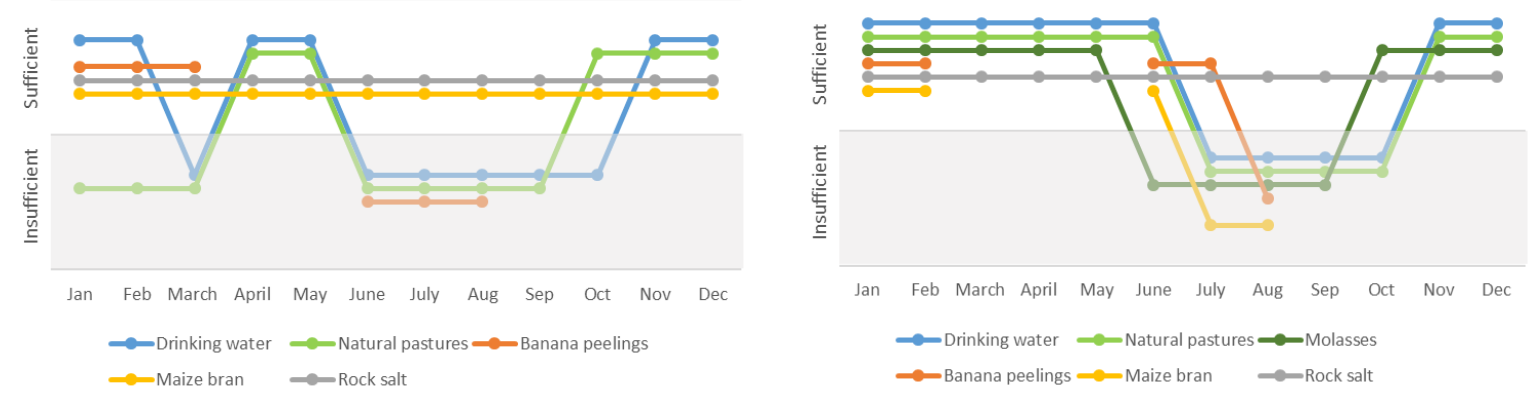

Bukanga (paddock)

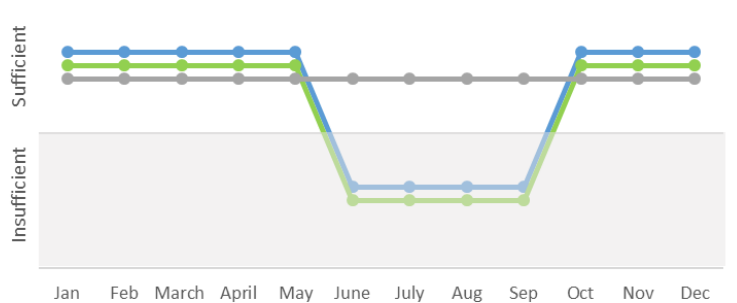

$\multimap$ Drinking water $\rightarrow$ Natural pastures $\rightarrow$ Rock salt

Figure 3c Perceived sufficiency of feedstuffs and cattle drinking water in a normal year, as perceived by farmers with fenced perimeter and fenced paddocked grazing systems in the workshop in Bukanga parish in Isingiro district.

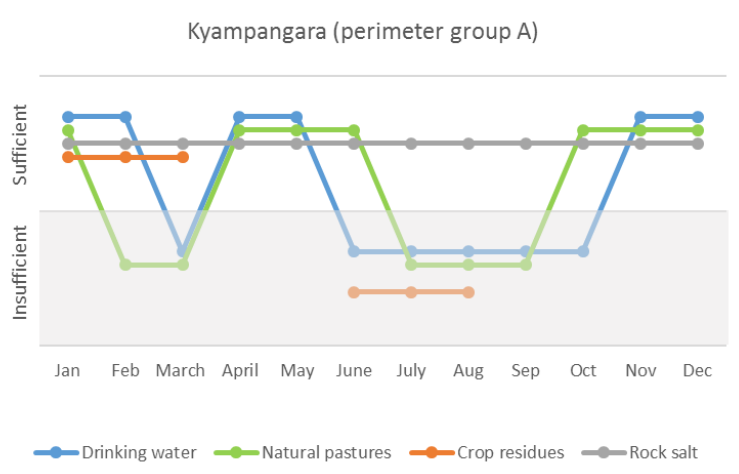

Rwempogo (perimeter)

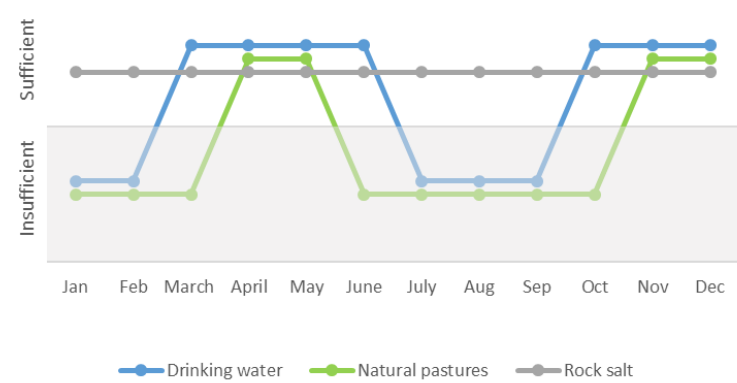

Kyampangara (perimeter group $B$

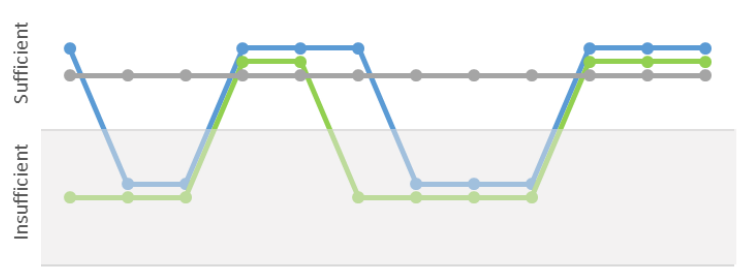

Jan Feb March April May June July Aug Sep Oct Nov Dec

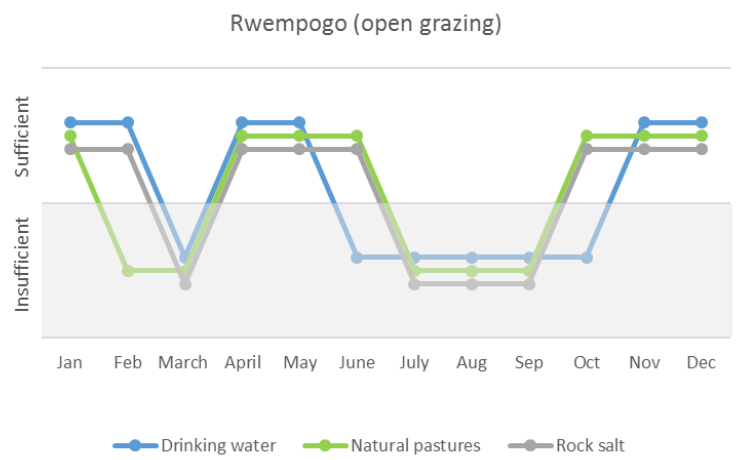

Figure 3d Perceived sufficiency of feedstuffs and cattle drinking water in a normal year, as perceived by farmers with fenced perimeter and open grazing systems in the workshops in Kyampangara village and Rwempogo village in Kiruhura district. 


\subsubsection{Prolonged droughts}

In all districts ${ }^{5}$ prolonged droughts impacted communities and dairy herds. Farmers created calendars to show impacts of prolonged drought in the years 1999, 2003 and 2016. In some focus groups farmers indicated the rainy season was very short or absent (see example in Figure $\mathrm{X}$ ). Besides drought, farmers indicated these dry periods were characterized by strong winds and high temperatures.

Table 3 shows the total list of effects of prolonged drought indicated by farmers in the workshops. Effects of prolonged droughts on dairy herds included: increase in diseases such as Anaplasmosis and Foot and Mouth disease, death of calves and cows due to insufficient feed and water, decrease in milk production levels, poor reproduction and abortion due to poor health and low body condition, and low prices of animals because of poor body condition. In one focus group farmers indicated crossbreds were more affected. With regard to effects on fodder production, farmers indicated nutritious pasture dried up and this gave room for the growth of less nutritious pasture, like Sporobolous sp.

\section{Table 3 Effects* of prolonged drought on communities and herd.}

\begin{tabular}{|c|c|c|c|c|}
\hline Effect & 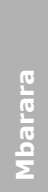 & $\frac{\text { है }}{\frac{\pi}{0}}$ & 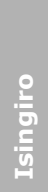 & $\frac{}{2}$ \\
\hline \multicolumn{5}{|l|}{ Community } \\
\hline Diseases in the community & $x$ & $x$ & $x$ & $x$ \\
\hline People migrating to other areas & $\mathrm{x}$ & & $\mathrm{x}$ & $x$ \\
\hline Reduced incomes, poverty & $x$ & & & $x$ \\
\hline School dropout & $x$ & & $x$ & $x$ \\
\hline Reduced markets for cattle products & $x$ & & $x$ & $x$ \\
\hline \multicolumn{5}{|l|}{ Herd } \\
\hline Increase in disease incidence & $x$ & $x$ & $x$ & $x$ \\
\hline Death of cattle & $x$ & & $x$ & $x$ \\
\hline Low levels of milk production & $x$ & $x$ & $x$ & $x$ \\
\hline Poor reproduction and abortion & $x$ & $x$ & $x$ & $x$ \\
\hline Low prices of animals because of poor body condition & & & $\mathrm{x}$ & \\
\hline
\end{tabular}

* As indicated by farmers (if not indicated, this does not necessarily mean the effect was absent)

Figure 4 shows an example of differences between a normal year and the prolonged drought in the year 2016, as perceived by farmers in Bukanga parish in Isingiro district. In 2016 droughts lasted from January to September and continued in November and December, with a very short rainy period in October. At community level, the prolonged drought period resulted in inadequate food as a result of crop failure, a lack of clean water for both domestic and animal use, conflicts amongst homes and farmers as a result of theft of little available food stuffs, poverty and reduced incomes, and school dropout because school fees could not be paid. On dairy farms, cattle died due to a lack of grass and water, disease incidences increased, and milk production levels decreased.

\footnotetext{
${ }^{5}$ At a different moment in the workshop, however, farmers in Sheema district indicated they have relatively stable weather and are not much affected by extreme drought or extreme wet seasons.
} 
Normal year (2014)

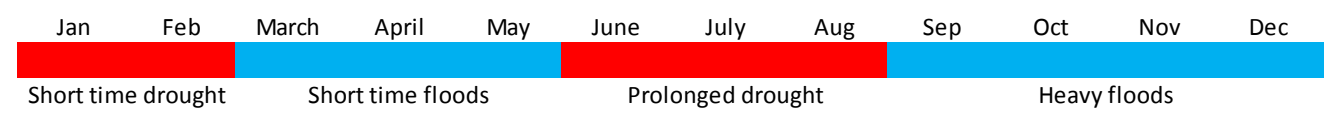

Dry year (2016)

\begin{tabular}{|l|l|}
\multicolumn{1}{|c}{ Drought, strong winds, hot te } \\
Inadequate food in the communities \\
School dropout \\
Lack of clean water \\
Conflicts amongst homes and farmers, theft \\
Reduced markets for cattle products \\
Increase in cattle diseases \\
Death of cattle \\
Low levels of milk production
\end{tabular}

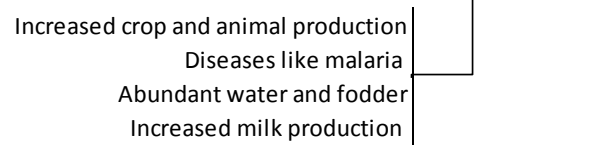

Figure 4 Perceived length of the dry season in a normal year and a dry year, and perceived effects of the prolonged drought in 2016 on communities and cattle herds of farms with a fenced perimeter grazing system in Bukanga parish in Isingiro district.

\subsubsection{Excess rainfall}

In all districts ${ }^{6}$ excess rainfall impacted communities and dairy herds. Farmers created calendars to show impacts of excess rainfall in the years 1997, 2000, 2004, 2005, 2011, 2012, 2013, and 2014. Farmers indicated rainy periods in these years were characterized by floods, landslides, strong winds, heavy precipitation and cold days.

Table 4 shows the total list of effects of excessive rainfall indicated by farmers in workshops. Floods caused rotting of grass, which led to cattle rejecting the grass, especially in the lowlands. In all districts farmers reported increased outbreaks of cattle diseases, including tick-borne diseases (e.g. East Coast Fever), Trypanosomiasis, pneumonia in calves, and foot rot. Also, in all districts farmers indicated lower milk yields because cattle were affected by diseases and insufficient time for grazing. In Mbarara district and Isingiro district farmers also indicated milk production increased of cows that were unaffected by disease. In some focus groups farmers reported increased numbers of flies affecting the milking process.

Table 4 Effects* of long-term excessive rainfall on communities and herds.

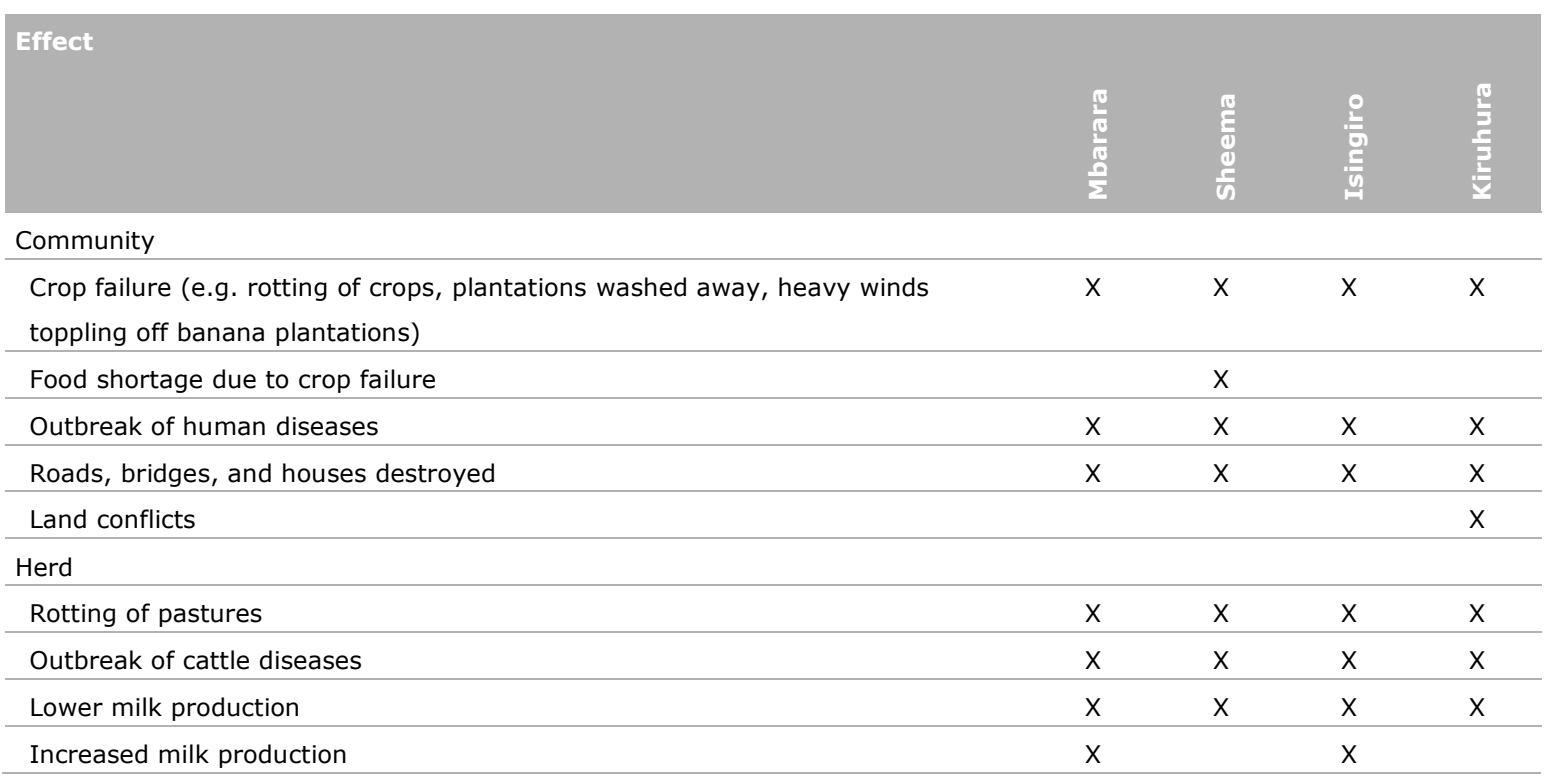

* As indicated by farmers (if not indicated, this does not necessarily mean the effect was absent)

\footnotetext{
${ }^{6}$ At a different moment in the workshop, however, farmers in Sheema district indicated they have relatively stable weather and are not much affected by extreme drought or extreme wet seasons.
} 
Figure 5 shows an example of differences between a normal year and an extremely wet year (2011), as perceived by farmers in Bukanga parish in Isingiro district. In 2011 the rainy seasons were longer than a normal year, with short dry periods in February and July. At community level, excessive rains resulted in increased food production and more water collection, but also in outbreaks of human diseases and rotten plantations. On dairy farms, milk production increased, but at the same time there were more outbreaks of cattle diseases such as foot and mouth disease.

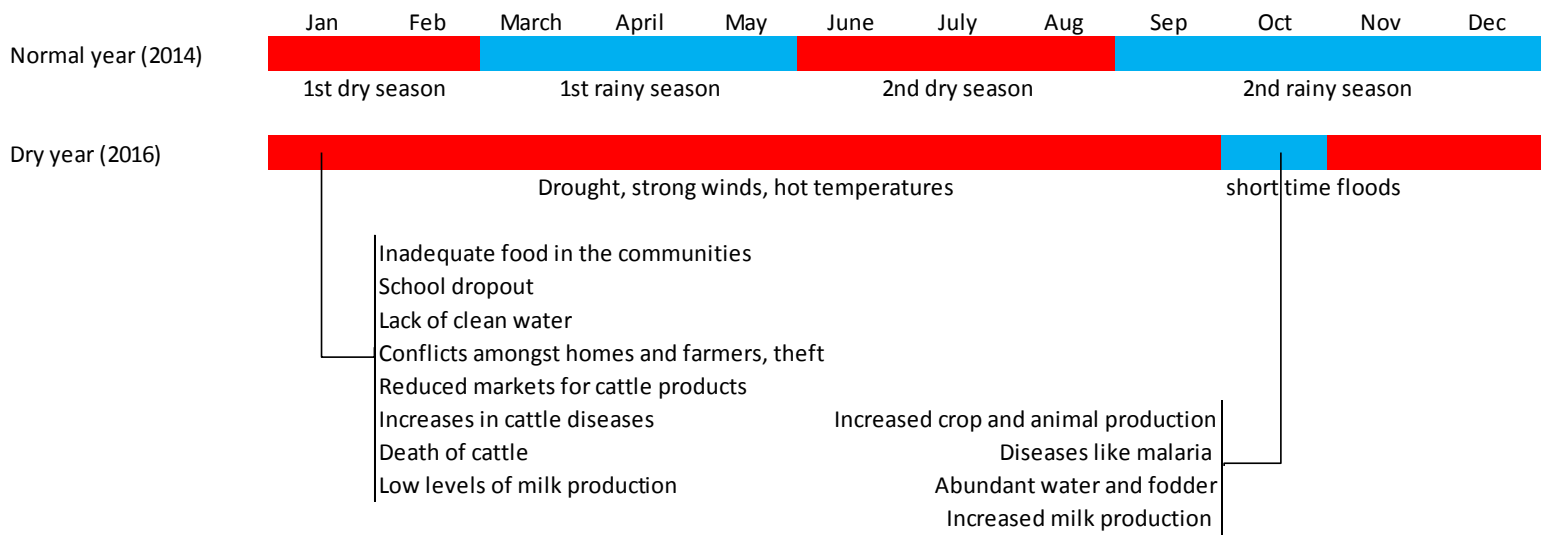

Figure 5 Effects of long-term excessive rainfall in 2011 on communities and cattle herds of farms with a fenced perimeter grazing system in Bukanga parish in Isingiro district.

\subsection{Current adaptation strategies}

To cope with the reduced intake from natural pastures, farmers in most focus groups fed alternative feeds during the dry seasons, such as banana peelings and stems, maize stover, brewers mash, and jackfruit. However, because even crop residues are often insufficient (especially in the second dry season), farmers employ other strategies to adapt to reduced feed and water availability. These strategies include efforts to increase feed resources, use of alternative water sources, reducing the herd size, and migration (Table 5). Adaptation strategies for reduced water availability were almost the same as those for reduced feed availability (Table 6).

Nearly all focus groups indicated alternative feeds, ferrying water, selling off cattle, and migrating cows were common strategies to adapt to insufficient feed and water availability (Table 5). Only farmers with fenced paddocks in Bukanga and with open grazing systems in Rwempogo did not mention alternative feeds as an adaptation option. The farmers with open grazing systems in Rwempogo used reduction of the herd size and migration as the only coping strategies, probably because alternative feed resources are not available. Farmers with a perimeter system in Rwempogo did not mention any adaptation strategy for reduced feed availability. 
In a few focus groups other strategies were mentioned, including weeding, grazing at night, rotational grazing, renting land, feeding fodder from wetlands, and stationing cattle at other farms during the dry season (Table 5).

Table 5 Current adaptation options of farmers during reduced feed availability in dry seasons.
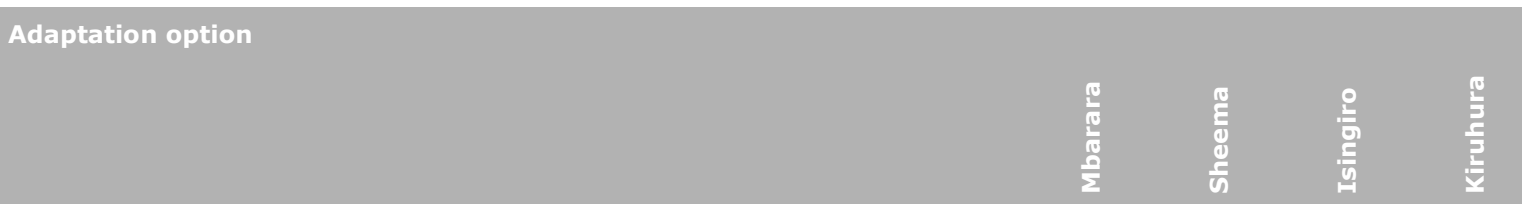

\begin{tabular}{|c|c|c|c|c|}
\hline \multicolumn{5}{|l|}{ Increase feed resources } \\
\hline Renting land & & & $x$ & $x$ \\
\hline Weeding to allow fresh pasture to grow & & $x$ & $x$ & \\
\hline Feeding at night & $x$ & $\mathrm{X}$ & & \\
\hline Selling off cattle & & $x$ & $x$ & $\mathrm{x}$ \\
\hline \multicolumn{5}{|l|}{ Migration } \\
\hline Migrating cows to other areas where there is pasture & & & $x$ & $\mathrm{X}$ \\
\hline Feeding from wetlands & & $x$ & & \\
\hline
\end{tabular}

To improve access to drinking water for cattle, farmers ferry water to refill the dams during dry seasons, construct valley tanks and bigger dams to accommodate large quantities of water, construct trenches to direct water into the dams during the rainy season, clear and clean water dams, and fence dams to prevent animals from defecating and directly tampering with water. One focus group mentioned rain water harvesting.

Table 6 Current adaptation options of farmers during reduced water availability in dry seasons.

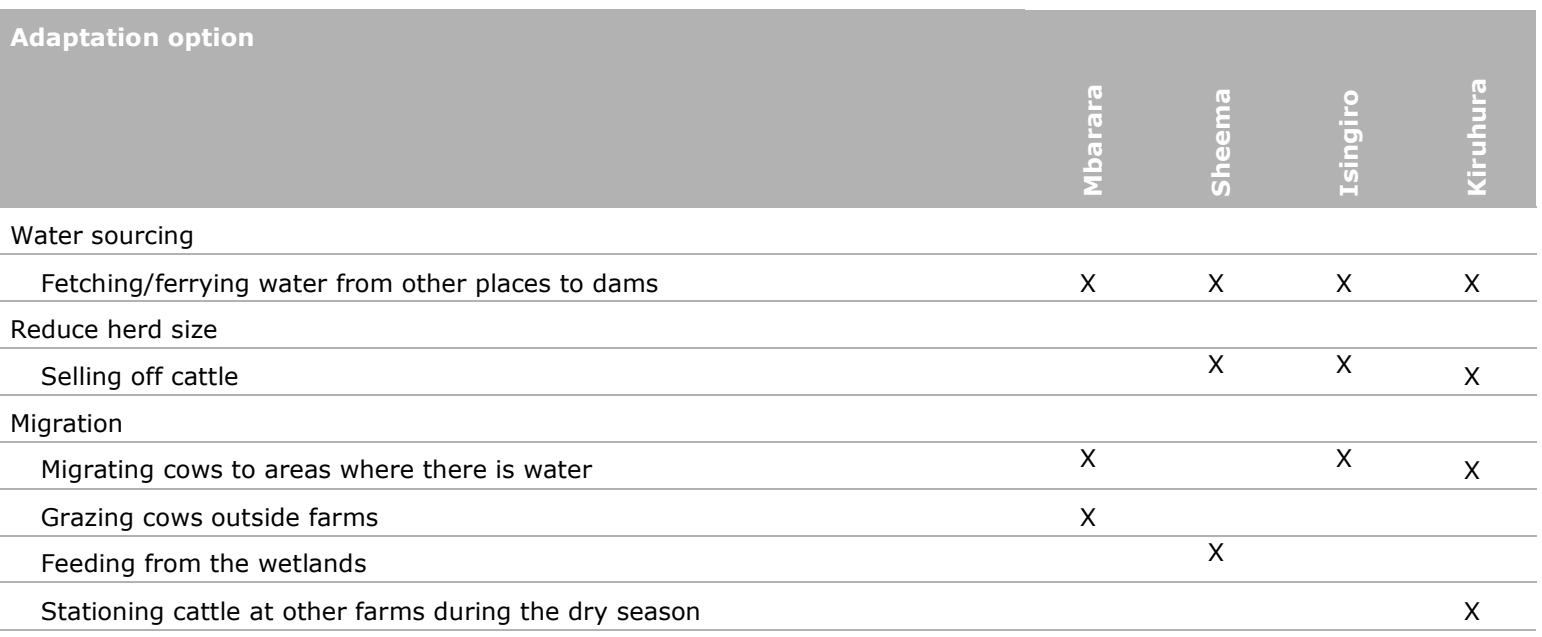

\subsection{Preferred adaptation options}

\subsubsection{Prolonged drought}

Whereas strategies to adapt to reduced feed and water availability were quite similar among focus groups, focus groups differed in terms of preferences for adaptation options: Ranked adaptation options per focus group are in Annex 1.

Short-term adaptation options most often mentioned (see Annex 1) per district were:

- Mbarara: sell cattle, migrate cattle, alternative feeds;

- Sheema: sell cattle/reduce herd size, alternative feeds / feed crop residues;

- Isingiro: migrate cattle, sell cattle, and ferry water / construct bigger dams; 
- $\quad$ Kiruhura: reduce herd size/sell cattle, migrate, ferry water.

Long-term adaptation options most often mentioned (see Annex 1) per district were:

- Mbarara: paddocking/perimeter fencing, clear farm fields, construct bigger dams;

- Sheema: construct (bigger) dams;

- Isingiro: clear farm fields, construct bigger dams/valley tanks;

- Kiruhura: construct bigger dams/valley tanks.

Other adaptation options mentioned in this ranking exercise were: night feeding, planting grasses, planting fodder grasses like Napier grass, planting trees, fencing wetlands, renting other land, grazing neighbors land, culling old cows, renovating water wells, acquiring loans, stocking veterinary drugs, improved breeds, and diversification to crop farming.

\subsubsection{Excess rainfall}

Ranked adaptation options per focus group are in Annex 2. Adaptation options most often mentioned by focus groups (see Annex 2) were:

- Deworming and vaccination

- $\quad$ Migrate cows to flood free areas

- Dig trenches for drainage and to direct water flow

- Fence farms.

Other adaptation options mentioned were use of alternative feeds, change calf pen to avoid rain from entering, separate calves from cows, intensified spraying for tick control, and expanded dams.

\subsection{Barriers and opportunities for adaptation}

Farmers' opinions of barriers and opportunities to realizing climate smart practices are shown in Table 7 and 8. Barriers most often mentioned were: limited capital, animal diseases, harsh climate/climate change, poor quality veterinary drugs, and insufficient training/sensitization. 


\begin{tabular}{|c|c|c|c|c|}
\hline Barrier & $\frac{\frac{20}{20}}{\frac{20}{20}}$ & 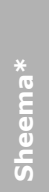 & 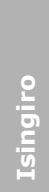 & 달 \\
\hline Limited capital & $\mathrm{x}$ & $x$ & $x$ & $x$ \\
\hline Harsh climate/climate change (mainly drought) & $x$ & $x$ & $x$ & $x$ \\
\hline Poor quality/scarce veterinary drugs & $x$ & $x$ & $x$ & $x$ \\
\hline Not enough trainings/sensitization & $x$ & $x$ & $x$ & $x$ \\
\hline Poverty/low income & $x$ & & $x$ & $x$ \\
\hline Poor breeds / access to alternative breeds & $x$ & & $x$ & \\
\hline Not enough land & $x$ & & & $x$ \\
\hline Costs of farm inputs & $x$ & & & \\
\hline
\end{tabular}

Negative attitudes towards modernization

Under-utilization of land $\quad x$

Infertile soils $\quad x$

\begin{tabular}{ll} 
Not enough extension workers & $X$ \\
\hline
\end{tabular}

Thieves

$\mathrm{X}$

Political interference/corruption

Poor infrastructure

* Farmers in Karera (Sheema district) indicated they have relatively stable weather and are not much affected by extreme drought or extreme wet seasons

Opportunities for realizing climate smart practices most often mentioned were: availability of a market for cattle products, presence of NGO's with trainings, sensitizations, and services, a supportive government, and being organized in co-operatives (access to services). Farmers in Karera (Sheema district) indicated their area is well adapted to extreme weather conditions due to the presence of wetlands and trees.

Table 8 Opportunities for realizing climate smart practices, as perceived by farmers.

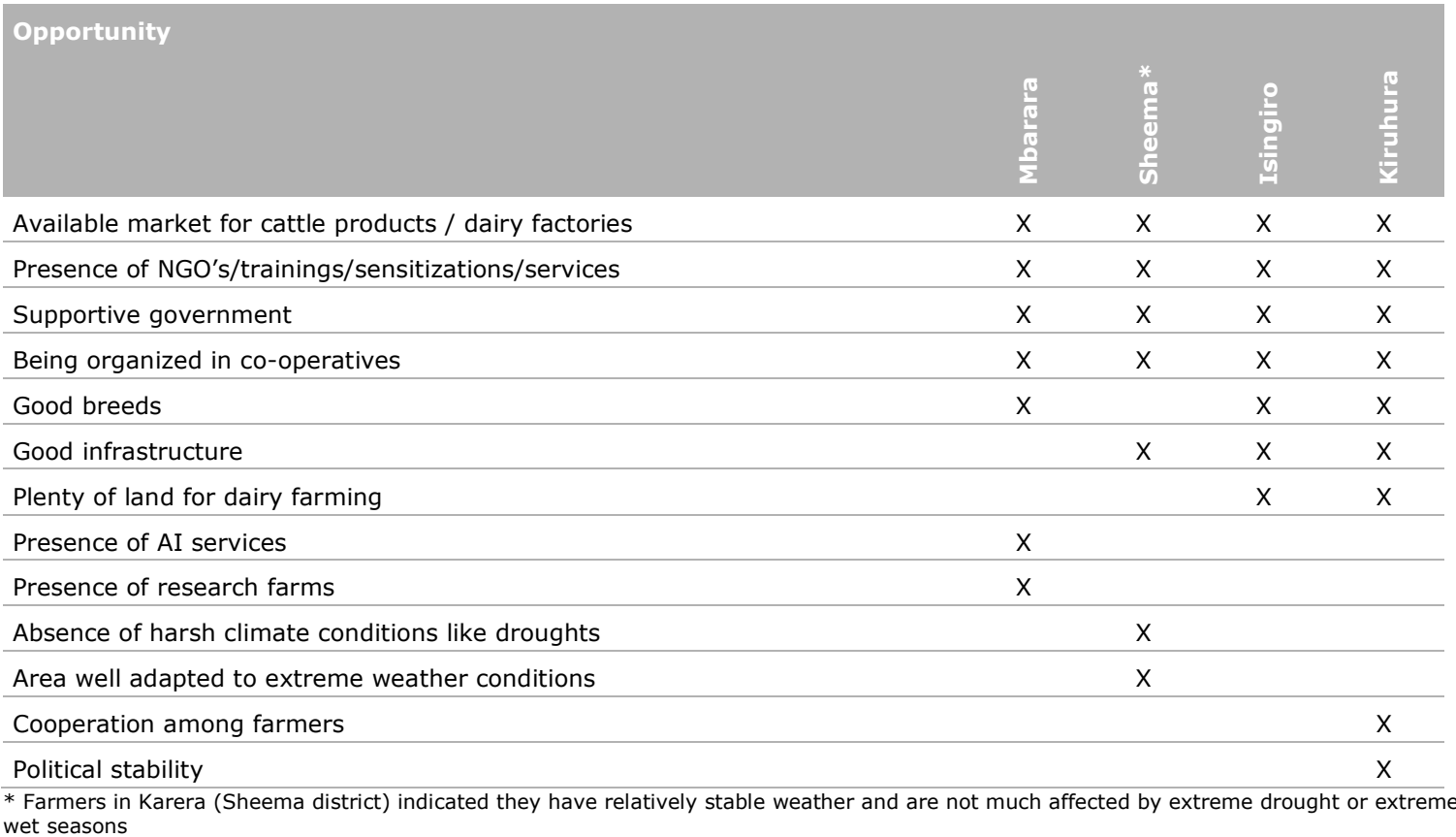




\section{$4 \quad$ Discussion \& conclusions}

This study showed that dairy farmers in southwest Uganda are experiencing severe feed and water shortages during the $2^{\text {nd }}$ dry season of normal years, and more severe feed and water shortages during extremely dry years. This strongly affects production and reproductive performance of herds, and increases disease incidence and mortality. To cope with droughts, farmers indicated that they use various strategies to increase access to feed and water resources, migrate cattle, or reduce the herd size. Extremely wet years were mainly associated with increased incidence of diseases, besides reduced milk yields.

In this study we focused on impacts of seasonal variability and extreme climate events (droughts and excess rainfall) rather than long-term changes in overall annual rainfall, temperature and $\mathrm{CO}_{2}$ concentrations in the air. Literature shows that climate change is expected to affect overall annual rainfall, temperature and $\mathrm{CO}_{2}$ concentrations, which in turn will impact plant productivity (including grassland), plant species composition and dynamics, animal heat stress, and disease emergence, spread, and distribution (Thorton et al., 2015). It has been suggested, however, that changes in overall annual rainfall and temperature in Uganda have little direct impact on livestock production systems (MWE, 2015b; based on IFPRI modelling results). On the other hand, Thornton et al. (2015) showed Aboveground Net Primary Productivity (ANPP) of rangelands in Uganda under the worst climate scenario (RCP8.5) may reduce by 35\% towards 2050 compared to 1971-1980, although the largest impacts are expected to take place in northern Uganda. In the report by MWE (2015b), it was stressed that modelling results were only for yield and area, whereas key impacts for livestock were expected to come from other climate change factors, particularly droughts, floods and diseases.

\section{Methodological limitations}

There are a number of methodological limitations to this study that should be taken into account when interpreting results:

- Because farmers participating in the workshops were not randomly selected, they were not necessarily representative of farmers in their district. Therefore, results cannot be generalized to the whole population of dairy farms in the 4 districts in this report, nor to all dairy farms in southwestern Uganda.

- We expect workshop facilitators influenced results, because: i) in the workshop reports facilitators did not always report the original answers of farmers but categorized some of the answers, causing that some of the results were similar across the workshops of the same facilitator (reporting bias), and ii) comprehensiveness of answers (e.g. number of coping strategies) differed significantly among enumerators.

- $\quad$ As is common in these type of studies, responses of farmers were likely subject to selfreporting bias, including social desirability bias, recall bias, and limited knowledge. For example, results were sometimes inconsistent across different exercises, such as reported feed rations and farmers in Karera reporting 'harsh climate' in one exercise, and being 'not much affected by extreme weather' in another exercise.

\section{Vulnerability to extreme climate events}

Although the nature of future climate variability and its impacts are still largely unknown, it will likely have substantial impacts on food availability and environmental security (Thornton et al., 2014). In this study we showed how historical seasonal variability and extreme climate events (mainly droughts and floods) affected dairy farming systems. Impacts of extreme climate events found in this study were in line with foreseen impacts of climate change in other literature (e.g. Kirui et al., 2015; Worldbank, 2013; Rojas-Downing et al., 2017; Thornton et al., 2009 and 2015). According to Thornton et al. (2009) climate change will affect dairy farming systems mainly through (i) changes in the quality and quantity of water and feed, (ii) increased heat stress, and (iii) increased risks of cattle diseases. 
Farmers indicated that changes in the quality and quantity of feed and water took place both in the second dry season of a normal year and during prolonged droughts and excess rainfall. Also, drought affected the quality of pastures, due to overgrazing and growth of less nutritious pasture species. In most districts pasture grass was replaced by crop residues in the dry season, but their availability were most often insufficient as well, forcing farmers to migrate with their cattle or to sell cattle. Similar to results of our study, Kirui et al. (2015) showed nearly half of the dairy farmers in Wakiso District in Uganda purchase crop residues in case of feed shortage. Dairy farming systems in Wakiso district are quite different from those in the present study, however, as farmers in Wakiso district keep cattle under zero grazing and have little area for fodder production. Kirui et al. (2015) also showed there is a relation between the increasing length of the dry spell and increased shortage of feed resources, disease incidence, and reduced milk production levels.

Heat stress was not explicitly mentioned by farmers in our study, and is not likely to play a significant role in Southwestern Uganda because of the high altitude and associated moderate ambient temperatures. Temperatures above 25-30 degrees Celsius may reduce feed intake of Bos taurus cattle by about $2 \%$ for every 1 degrees increase, affecting their production and reproduction (NRC, 1981; Timmerman et al., 2018). However, it is well known different breeds respond differently to heat stress, and Bos taurus cattle are more sensitive to heat stress than Bos indicus breeds (e.g. Beatty et al., 2006).

Disease incidence increased during prolonged drought and excess rainfall, according to farmers in our study (Foot and Mouth disease, tick-borne diseases (incl. Anaplasmosis), foot rot, Trypanosomiasis, and pneumonia). Changes in the emergence, spread and distribution of crop and livestock diseases, pests and weeds are known to be affected by climate change (e.g. Thornton and Herrero, 2014). Challenges of controlling pests and diseases can be amplified by other local conditions, such as the ineffectiveness of acaricides for tick control during rainy seasons indicated by farmers in this study. Long-term use of acaricides is known to generate acaricide resistance of many tick species worldwide (Abbas et al., 2014). To preserve efficacy, Abbas et al. propose various options for resistance management, including rationale use of acaricides, vaccination, nutritional management, use of botanicals, improving genetic resistance in cattle, and pasture management. Bos indicus cattle breeds and their cross-breeds are naturally less susceptible to tick-borne diseases. Ankole cattle are a hybrid Bos taurus indicus and have been shown to possess similar levels of tolerance to various tick species as Uganda's Nkedi Zebu cattle ( $B$. indicus), but with a poorer capability of mounting infections (Magona et al., 2011). Poor quality feed has shown to result in a higher susceptibility of Bos taurus breeds and $B$. indicus $\times$ B. taurus cross-breeds to tick-borne diseases (Tolleson et al., 2010).

\section{Current adaptation strategies to extreme climate events}

Various adaptation strategies were reported in the present study, including options to increase feed resources, to reduce the herd size, and to migrate cattle. The latter two strategies, reducing the herd size and migration, were also used to increase water resources for cattle, besides ferrying water. Choice of breed was not explicitly mentioned as an adaptation strategy in the exercise of creating a climate calendar (i.e. results of paragraph 3.3), but was mentioned as an adaptation strategy in discussions and the pairwise ranking exercise (paragraph 3.4). Most farmers preferred exotic breeds or cross-breeds (mainly Holstein-Friesian) because of high milk yields, whereas some farmers preferred local breeds due to their hardiness and disease resistance.

Options to increase feed resources reported in this study were feeding of alternative feeds (e.g. crop residues, some farmers mentioned conserved fodder), rotational grazing, weed control, feeding at night, and renting land. Even in a normal year, however, alternative feeds were often insufficient during the second dry season. Particularly crop residues were an important dry-season feed resource for most farmers. The quantity and quality of crop residues may be increasingly affected by climate change (Thornton and Herrero, 2014). According to climate change modeling results of MAAIF (2015, based on IFPRI modeling results) cassava, potato and sweet potato yields in Uganda will be substantially lower in 2050 as a result of climate change, whereas reductions are smaller or yet unclear for other crops (e.g. millet, sorghum, maize). These results are focused on grain yield, however, though Niang et al. (2014) expected maize stover availability will decrease in East Africa, as a result of water scarcity. In the present study, most farmers fed banana crop residues. Banana 
productivity is highly dependent on rainfall, and drought stress is the main yield constraint in southwest Uganda (Wairegi et al., 2010). It is yet uncertain, however, if banana production will increase or decline because results vary among climate scenarios (Sabiiti et al. 2016). Also, effects on banana crop residues are still unknown. Various techniques are available to reduce the vulnerability of banana production to prolonged drought (e.g. Sabiiti et al. 2016).

Other strategies of farmers in the present study to increase feed resources were in line with other literature, including fodder banks, spell and rotational grazing, and weeding to allow fresh pasture to grow (e.g. Petersen et al., 2003). In the present study we did not find an indication that farms with fenced paddocks for rotational grazing were performing better than farms with fenced perimeter systems. Only 15 farmers in our study fed conserved fodders (silage and hay). Balikowa (2011) also found that only few households in southwestern Uganda feed conserved fodder and grow fodder crops. Reasons for not feeding conserved fodders in our study were the lack of knowledge and skills, labour, high costs in combination with limited financial resources, and some farmers indicated their herd does not require conserved fodder.

With regard to reduction of the herd size, farmers in the present study indicated they sold or slaughtered cattle when feed and water resources became insufficient. Future climate change may further impact stocking rates due to changes in pasture growth, since the carrying capacity of pastures depends on climate and soil conditions and is greatly influenced by the average length of the growing season.

\section{Other adaptation options}

Although more adaptation options have been described in literature besides those indicated in the present study, what works in particular situations is highly dependent on the geographical and socioeconomic context of the specific farming system (Thornton and Herrero, 2014). For example, feeding crop residues was not common to farmers in Rwempogo village in Kiruhura district, and farmers of Karera district indicated they were not much affected by extreme droughts or extreme rainfall. For farmers with open grazing systems in Kiruhura district, adaptation options such as stress-tolerant cattle breeds and animal species, and the ability to migrate over long distances may be more important, whereas improving pasture management and availability of alternative feeds (incl. fodder preservation) may be more relevant in areas like Mbarara district.

Other adaptation options suggested in literature are, i.a. (Thornton et al., 2014 and 2015; Escarcha et al., 2018; Chang-Fung-Martel et al., 2017):

- $\quad$ restoration of degraded pasture; planting trees and legumes; sowing drought-resistant grass and fodder species;

- $\quad$ preservation of feed and fodder, and food products to prevent losses; less burning of crop residues (Kirui et al., 2015);

- $\quad$ water use efficiency, harvesting and retention (e.g. double digging for water retention; Kirui et al., 2015);

- provision of shade against heat stress;

- $\quad$ stress-tolerant breeds and/or species;

- ability to migrate cattle over long distances;

- diversification of plant and livestock activities, species, and breeds, and other off-farm income options;

- $\quad$ use of weather information or early warning systems; and

- weather-index insurance.

\section{Coping vs. mitigation of risks}

Current adaptation strategies of farmers seemed to be focused mostly on coping with effects of extreme climate events (e.g. reducing the herd size, migrating cattle) rather than the prevention and mitigation of climate risks (e.g. fodder banks, rotational grazing, fodder conservation). Introducing adaptation options that contribute to less exposure and sensitivity to extreme climate events may contribute to increased resilience of dairy farming systems. For example, by providing shade cattle are less exposed to high temperatures, and by introducing fodder banks, drought resilient pastures, or hay and silage farming systems are less sensitive to changes in pasture availability and quality. The 
feasibility of such interventions in terms of cost-effectiveness, practical implementation, and overall resilience of farming systems and households, however, need to be explored.

\section{Conclusions and recommendations}

It was concluded that dairy farming systems in southwest Uganda are affected by climate variability mainly through the reduced quantity and quality of feed and water resources, and changes in disease incidence. This affects production and reproductive performance of herds, and increases disease incidence and mortality. Farmers use various strategies to cope with these challenges, including management of feed and water resources, migration of cattle, and reduction of the herd size.

As current adaptation strategies of farmers appeared mostly short-term coping strategies, other adaptation strategies should be explored. These adaptation strategies should be focused on (i) improving the quantity and quality of feed and water resources during periods of drought and excess rainfall, (ii) prevention and management of cattle diseases, and (iii) increasing overall resilience of animals, farming systems and households (e.g. through breeding, health care, diversification, etc.). Measures should be tailored to the different circumstances of farms and types of farming systems (e.g. open vs. fenced grazing system, availability of crop residues). Promising adaptation options should be identified and tested locally with farmers in different locations.

It should be emphasized that there would appear to be no silver bullets, i.e. options standing out that have high potential for enhancing climate resilience of dairy farms that do not also have constraints to their adoption (Thornton and Herrero, 2014). There are limits to what can be achieved in increasing resilience through agricultural management. Different options will be needed in different circumstances, and their feasibility will depend on local conditions.

\section{Acknowledgements}

This research was carried out as part of of 'The Inclusive Dairy Enterprise' (TIDE) project, which is commissioned and funded by the Embassy of the Kingdom of the Netherlands and implemented by SNV Netherlands Development Organisation in Uganda. The author would like to thank the staff of SNV Uganda for executing the workshops, and Paul Kimbugwe (SNV Uganda), Annabelle Daburon (Wageningen Centre for Development Innovation), Asaah Ndambi, and Bram Wouters (Wageningen Livestock Research) for their advice and constructive comments to this report. 


\section{References}

Abbas, R.Z., M. Arfan, D.D. Colwell, J. Gilleard, Z. Iqbal. 2014. Acaricide resistance in cattle ticks and approaches to its management: the state of play. Vet. Parasitol. (203): 6.

Agriterra, 2012. Identification of livestock investment opportunities in Uganda. Agriterra, Arnhem, the Netherlands.

Balikowa, 2011. Dairy development in Uganda: A Review of Uganda's Dairy Industry. GOU/FAO Dairy Project, TCP/UGA/3202(D).

Beatty DT, Barnes A, Taylor E, Pethick D, McCarthy M, Maloney SK. 2006. Physiological responses of Bos taurus and Bos indicus cattle to prolonged, continuous heat and humidity. J Anim Sci. 84(4): 972-85.

Chang-Fung-Martel, J.; Harrison, M. T.; Rawnsley, R.; Smith, A.P.; Meinke, H. 2017. The impact of extreme climatic events on pasture-based dairy systems: a review. Crop and Pasture Science 68(12):1158-1169.

Escarcha, JF, JA Lassa, and KK Zander. 2018. Livestock Under Climate Change: A Systematic Review of Impacts and Adaptation. Climate 6 (3): 1-17.

Kirui, W, Muthama JN, Opere AO and Ngaina J. 2015. Influence of climate change on smallholder dairy productivity: A case of Kosirai, Kenya, and Namayumba, Uganda. Journal of Agricultural Science Research Vol. 4(6), pp. 109-116.

MAAIF, 2010. Agriculture for Food and Income Security - Agriculture Sector Development Strategy and Investment Plan: 2010/11- 2014/15. Uganda.

MAAIF and MWE, 2016. Uganda Climate Smart Agriculture Country Program 2015-2025. Jointly implemented by Ministry of Agriculture, Animal Industry and Fisheries (MAAIF) and Ministry of Water and Environment (MWE). Uganda.

Magona, J. W., J. Walubengo, and F. Kabi. 2011. "Response of Nkedi Zebu and Ankole cattle to tick infestation and natural tick-borne, helminth and trypanosome infections in Uganda", Tropical Animal Health and Production, vol. 43, no. 5, pp. 1019-1033.

MWE, 2015a. Uganda National Climate Change Policy, Kampala, Uganda.

MWE, 2015b. Economic Assessment of the Impacts of Climate Change in Uganda. National Level Assessment: Agricultural Sector report. March 2015. Kampala, Uganda.

Mwongera, C., et al. (2017). Climate smart agriculture rapid appraisal (CSA-RA): A tool for prioritizing context-specific climate smart agriculture technologies. Agricultural Systems 151: 192-203.

NAMA Uganda. Nationally Appropriate Mitigation Action on Climate-Smart Dairy Livestock Value Chains in Uganda. Ministry of Agriculture, Animal Industry and Fisheries, United Nations Development Programme.

NAPA, 2007. Climate Change. Uganda National Adaptation Programmes of Action.

Niang I, Ruppel OC, Abdrabo MA, Essel A, Lennard C, Padgham J, Urquhart P, 2014. Africa. In: Climate Change 2014: Impacts, Adaptation, and Vulnerability. Part B: Regional Aspects. Contribution of Working Group II to the Fifth Assessment Report of the Intergovernmental Panel on Climate Change [Barros VR, Field CB, Dokken DJ and 13 others (eds.)]. Cambridge University Press, Cambridge, United Kingdom and New York, NY, USA, pp. 1199-1265.

NRC, 1981. Effect of Environment on Nutrient Requirements of Domestic Animals. Subcommittee on Environmental Stress, National Research Council (NRC). Washington, DC, National Academy Press.

Petersen P.H., Ndumu, D.B., Kiwuwa, G.H., Kyomo, M.L., Semambo, D.K.N., Rowlands, G.J., Nagda, S.N. \& Nakimbugwe, H. 2003. Characteristics of Ankole Longhorn cattle and their production environments in South Western Uganda: milk offtake and body measurements. AGRI 2003, 34: 19.

Rojas-Downing, M.M., Nejadhashemi, A.P., Harrigan, T., Woznicki S.A. 2017. Climate change and livestock: Impacts, adaptation, and mitigation. Climate Risk Management 16: 145-163.

Sabiiti G. et al. (2018) Adapting Agriculture to Climate Change: Suitability of Banana Crop Production to Future Climate Change Over Uganda. In: Leal Filho W., Nalau J. (eds) Limits to Climate Change Adaptation. Climate Change Management. Springer, Cham.

Scanlan J , Mckeon G , Day K, Mott J , Hinton A (1994) Estimating safe carrying capacities of extensive cattle-grazing properties within tropical, semi-arid woodlands of North-Eastern Australia. The Rangeland Journal 16, 64-76. doi:10.1071/RJ9940064 
Thornton, P.K., Van de Steeg, J., Notenbaert, A., Herrero, M. 2009. The impacts of climate change on livestock and livestock systems in developing countries: A review of what we know and what we need to know. Agricultural Systems 101 (3): 113-127.

Thornton PK, Boone RB, J Ramirez-Villegas 2015. Climate change impacts on livestock. CCAFS Working Paper no. 120. CGIAR Research Program on Climate Change, Agriculture and Food Security (CCAFS). Copenhagen, Denmark. Available online at: www.ccafs.cgiar.org .

UNDP, 2012. Climate Change Country Profiles: Uganda. United Nations Development Programme.

UNDP, 2017. Nationally Appropriate Mitigation Action on 'Climate-Smart Dairy Livestock Value Chains in Uganda.

Wairegi, L. W. I., Van Asten, P. J., Tenywa, A., \& Bekunda, M. (2010). Abiotic constraints override biotic constraints in East African highland banana systems. Field Crops Research, 117, 146-153.

Worldbank, 2013. Turn down the heat: Climate Extremes, Regional Impacts, and the Case for Resilience. Worldbank, Washington DC. 


\section{Appendix 1 Preferred adaptation options during prolonged droughts}

Preferred adaptation options of farmers in Mbarara district during prolonged droughts.

\begin{tabular}{|c|c|c|c|c|}
\hline & $\begin{array}{l}\text { Kashaka } \\
\text { (perimeter) }\end{array}$ & $\begin{array}{l}\text { Kashaka } \\
\text { (paddock) }\end{array}$ & $\begin{array}{l}\text { Karama } \\
\text { (perimeter) }\end{array}$ & $\begin{array}{l}\text { Karama } \\
\text { (paddock) }\end{array}$ \\
\hline \multicolumn{5}{|c|}{ Measures taken instantly: } \\
\hline 1 & Night feeding & Sell cattle & Sell cattle & Alternative feeds \\
\hline 2 & Move cattle to wetlands & Rent other land & Construct bigger dams & Sell cows \\
\hline 3 & Feed crop residues & Alternative feeds & Acquire loans & Migrate cattle \\
\hline 4 & $\begin{array}{l}\text { Move cattle to other places } \\
\text { for water }\end{array}$ & Clear farm fields & Refill dams & Graze neighbors land \\
\hline 5 & Sell cattle & & Migrate cattle & \\
\hline \multicolumn{5}{|c|}{ Measures taken on the longer term: } \\
\hline 1 & Widen dams & N.A. & Clear farm fields & Clear farm fields \\
\hline 2 & Plant Napier grass & & Paddocking / silage and hay & Paddocking \\
\hline 3 & Perimeter fencing & & & Construct bigger dams \\
\hline 4 & Fence wetlands & & & \\
\hline
\end{tabular}

Preferred adaptation options of farmers in Sheema district during prolonged droughts.

\begin{tabular}{lll} 
& $\begin{array}{l}\text { Karera } \\
\text { (perimeter) }\end{array}$ & $\begin{array}{l}\text { Karera } \\
\text { (paddock) }\end{array}$ \\
\multicolumn{2}{l}{ Measures taken instantly: } \\
\hline 1 & Reduce herd size & Clear farm fields \\
\hline 2 & Feed crop residues & Alternative feeds \\
\hline 3 & Feed from wetlands & Stock veterinary drugs \\
\hline 4 & Feed at night & Sell cattle \\
\hline & & \\
\hline Measures taken on the longer term: & \\
\hline 1 & Construct dams & Construct bigger dams \\
\hline 2 & Plant pasture & Paddocking \\
\hline 3 & & Fencing \\
\hline
\end{tabular}


Preferred adaptation options of focus groups in Isingiro district during prolonged droughts.

\begin{tabular}{|c|c|c|c|}
\hline & Bukanga (perimeter A) & Bukanga (perimeter B) & Bukanga (paddock) \\
\hline \multicolumn{4}{|c|}{ Measures taken instantly: } \\
\hline 1 & Fetch water & Sell cattle & Ferry water from gov. dams \\
\hline 2 & Feed crop residues & Construct bigger dams & Sell cows \\
\hline 4 & Migrate cattle & Refill dams & \\
\hline 5 & & Acquire loans & \\
\hline \multicolumn{4}{|c|}{ Measures taken on the longer term: } \\
\hline 4 & Plant trees & & \\
\hline
\end{tabular}

Preferred adaptation options of focus groups in Kiruhura district during prolonged droughts.
Kyampangara
Kyampangara
Rwempogo
Rwempogo
(perimeter A)
(perimeter B)
(perimeter)
(open grazing)

Measures taken instantly:

\begin{tabular}{lllll}
\hline 1 & Reduce herd size & Ferry water to own dams & Ferry water from boreholes & Sell cattle / Eat young bulls \\
\hline 2 & Clear and fence farm fields & Rent land & Sell cows / Migrate cattle & Take cattle to friends \\
\hline 3 & Migrate & Migrate & & \\
\hline 4 & & Sell cattle & \\
\hline
\end{tabular}

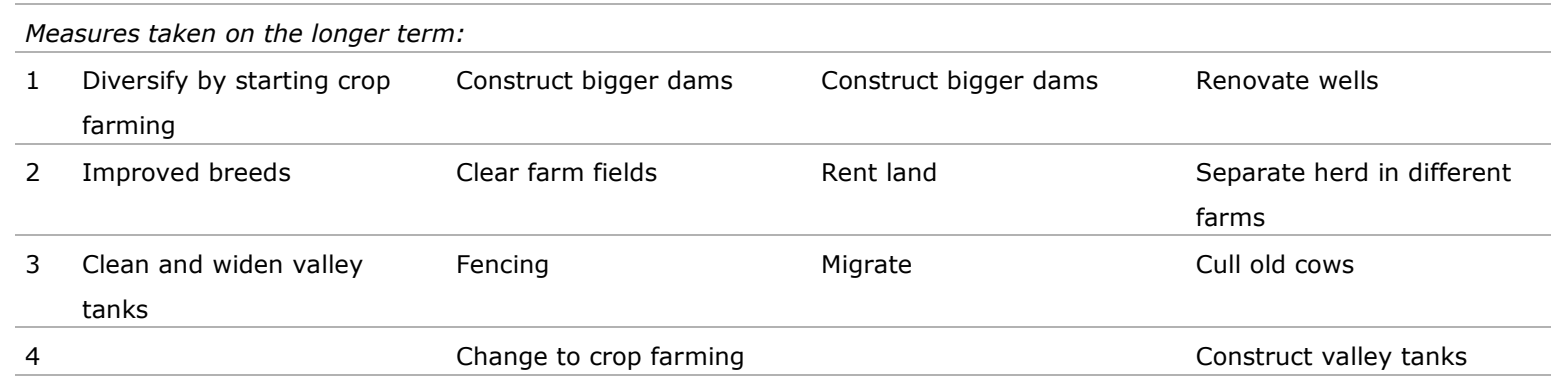




\section{Appendix 2 Preferred adaptation options during excess rainfall}

Preferred adaptation options of farmers in Mbarara district during excess rainfall.

\begin{tabular}{|c|c|c|c|c|}
\hline & $\begin{array}{l}\text { Kashaka } \\
\text { (perimeter) }\end{array}$ & $\begin{array}{l}\text { Kashaka } \\
\text { (paddock) }\end{array}$ & $\begin{array}{l}\text { Karama } \\
\text { (perimeter) }\end{array}$ & $\begin{array}{l}\text { Karama } \\
\text { (paddock) }\end{array}$ \\
\hline 1 & Fence wetlands & $\begin{array}{l}\text { Fence the farms / Clear } \\
\text { the farms out of bushes }\end{array}$ & $\begin{array}{l}\text { Deworming and } \\
\text { vaccination }\end{array}$ & Deworming and vaccination \\
\hline 2 & Dug trenches & Alternative feeds & & $\begin{array}{l}\text { Construct trenches to direct easy } \\
\text { flow of flooded water. }\end{array}$ \\
\hline 3 & & & & $\begin{array}{l}\text { Migrate cows to other flood free } \\
\text { areas. }\end{array}$ \\
\hline
\end{tabular}

Preferred adaptation options of farmers in Sheema district during excess rainfall.

\begin{tabular}{lll} 
& $\begin{array}{l}\text { Karera } \\
\text { (perimeter) }\end{array}$ & $\begin{array}{l}\text { Karera } \\
\text { (paddock) }\end{array}$ \\
\hline 1 & N.A. & Deworming and vaccination \\
\hline 3 & & Separate calves from cows \\
\hline 3 & & Construct trenches to direct water flows \\
\hline
\end{tabular}

Preferred adaptation options of focus groups in Isingiro district during excess rainfall.

\begin{tabular}{llll} 
& Bukanga (perimeter A) & Bukanga (perimeter B) & Bukanga (paddock) \\
\hline 1 & Deworming and vaccination & N.A. & Deworming and vaccination \\
\hline 3 & & Migrate cows to flood free areas \\
\hline
\end{tabular}

Preferred adaptation options of focus groups in Kiruhura district during excess rainfall.

\begin{tabular}{lllll} 
& $\begin{array}{l}\text { Kyampangara } \\
\text { (perimeter A) }\end{array}$ & $\begin{array}{l}\text { Kyampangara } \\
\text { (perimeter B) }\end{array}$ & $\begin{array}{l}\text { Rwempogo } \\
\text { (perimeter) }\end{array}$ & N.A. \\
\hline 1 & Intensified spraying to control ticks & Deworming and vaccination & N.A. & \\
\hline 2 & Vaccinated & Fence farms & & \\
\hline 3 & Expanded dams & & & \\
\hline
\end{tabular}


Wageningen Livestock Research

\section{P.O. Box 338}

$6700 \mathrm{AH}$ Wageningen

The Netherlands

T +31 (0)317483953

info.livestockresearch@wur.nl

www.wur.nl/livestock-research

Wageningen Livestock Research Report
The mission of Wageningen University and Research is "To explore the potential of nature to improve the quality of life". Under the banner Wageningen University \& Research, Wageningen University and the specialised research institutes of the Wageningen Research Foundation have joined forces in contributing to finding solutions to important questions in the domain of healthy food and living environment. With its roughly 30 branches, 5,000 employees and 10,000 students, Wageningen University \& Research is one of the leading organisations in its domain. The unique Wageningen approach lies in its integrated approach to issues and the collaboration between different disciplines. 


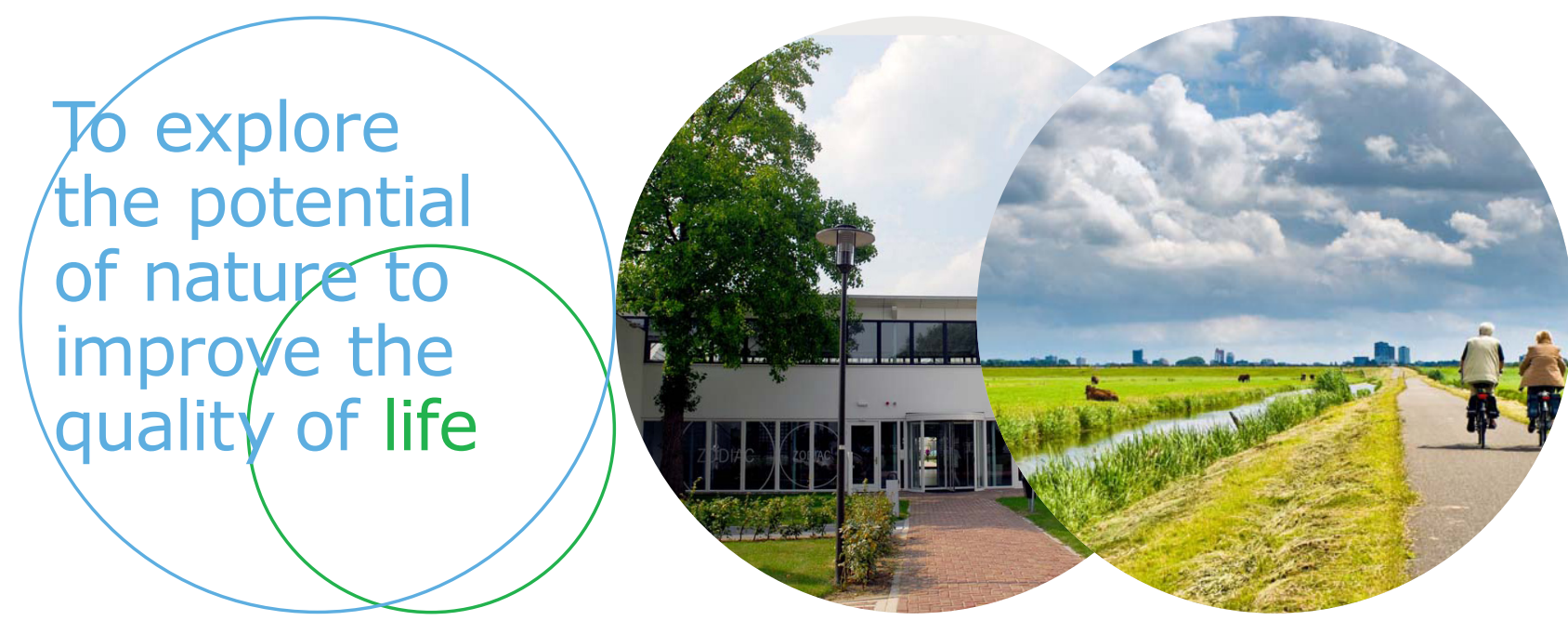

Wageningen Livestock Research P.O. Box 338

6700 AH Wageningen

The Netherlands

T +31 (0)31748 3953

E info.livestockresearch@wur.nl www.wur.nl/livestock-research

Wageningen Livestock Research creates science based solutions for a sustainable and profitable livestock sector. Together with our clients, we integrate scientific knowledge and practical experience to develop livestock concepts for future generations.

Wageningen Livestock Research is part of Wageningen University \& Research. Together we work on the mission: 'To explore the potential of nature to improve the quality of life'. A staff of 6,500 and 10,000 students from over 100 countries are working worldwide in the domain of healthy food and living environment for governments and the business community-at-large. The strength of Wageningen University \& Research lies in its ability to join the forces of specialised research institutes and the university. It also lies in the combined efforts of the various fields of natural and social sciences. This union of expertise leads to scientific breakthroughs that can quickly be put into practice and be incorporated into education. This is the Wageningen Approach. 